\title{
A feedstock supply model integrating the official organization for China's biomass generation plants
}

\author{
Xingping Zhang ${ }^{\text {a, b }}$, Kaiyan Luo ${ }^{\text {a, * }}$, Qinliang Tan ${ }^{\text {a, b }}$ \\ ${ }^{a}$ School of Economics and Management, North China Electric Power University, Beijing 102206, \\ China \\ ${ }^{\mathrm{b}}$ Research Center for Beijing Energy Development, Beijing 102206, China
}

\begin{abstract}
Shortage of feedstock has hindered the development of China's biomass power generation because it is highly difficult to collect straw in China. We pioneered a new feedstock supply model in which the formal official organization of villagers' committees is introduced. Different from the previous feedstock supply patterns, the immaterial utility of relative stakeholders and the impact of villagers' committees on farmers' behavior are considered in this paper. To compare this pattern's performance with that of the conventional ones, this paper developed a multi-agent model specifically for China's situation. We applied the model to simulate the operation of a biomass supply chain. The results show that the proposed feedstock supply pattern can significantly increase the profits of biomass plants, biomass supply amounts, and farmers' participation, and in contrast with the broker pattern, it can lower feedstock prices through disintermediation. Sensitivity analyses show that preferential feed-in tariffs are still necessary for biomass power and that the new pattern can ease the government's subsidy burdens. Additionally, farmers' opportunity costs for supplying biomass, their perceptions of immaterial utility and the cooperative's financial resource schemes of the public service foundation all have differing impacts on the achievement of the new pattern.
\end{abstract}

Keywords: biomass generation, feedstock supply chain, multi-agent simulation

\footnotetext{
* Corresponding author. Tel: +86 18510513026. E-mail address: 1ky 920909@ncepu.edu.cn (K. Luo).
} 


\section{Introduction}

At the present time, socioeconomic progress is challenged by environmental deterioration. Exploiting renewable energies, which are associated with both economical and efficient production and operation patterns has become the orientation for energy and industry policies. Biomass is a promising renewable energy that is viewed as carbon neutral in that its emissions are ultimately absorbed in future growth. Generally, the biomass utilization pathways include village-scale and industrial-size biogas and biofuel (solid pellet fuel, bioethanol, biodiesel, etc.) as well as power generation that could, if implemented with appropriate technologies, provide clean electricity, mitigate mist and haze, and increase employment opportunities for farmers (Moore et al., 2013; Zhang et al., 2010).

One area of research related to biomass-to-electricity pathways is the field of feedstock supply chain management. First, because the biomass feedstock supply chain features higher costs, some researchers conducted cost analyses of the logistical links of procurement, transportation, storage and preprocess (Zhang et al., 2013). Second, in order to reduce costs and improve efficiency, supply chain design has become one of the solutions. Rentizelas et al. (2009), Bojić et al. (2013), Hu et al. (2013), Kaundinya et al. (2013), Y. Sun et al. (2013) and Viana et al. (2010) probed into the problems of storage, transportation and the locations of biomass plants or warehouses. Third, the technique of computer simulation was popularized in studies of supply chains for biomass power generation that were intended to integrate the issues above, i.e., transport, storage, location and technical specifications for biomass plants (Mobini et al., 2011; Yu, 2011). Last but not least, in view of the large amount of agricultural biomass in China's rural areas, Chen and Chen (2014), Yang and Chen (2014a, 2014b), and Dai et al. (2015) conducted economic, energy and environmental evaluations on the biogas-linked production system with the emergy analysis and life cycle assessment (LCA).

China, a large agricultural country with abundant biomass resources (Liu et al., 
2014) has been devoted to promoting the industry of biomass power generation. The theoretical annual production of China's agri-biomass resources is about 870 million tons (440 million tons of coal equivalent), and about 400 million tons (200 million tons of coal equivalent) are available as energy sources ${ }^{1}$, which is sufficient for a year's operation of China's installed biomass-based power plants at the full capacity, and the 2015 (3.6 times) and 2020 (1.6 times) goals of generated bio-electricity. Since the first biomass plant of direct combustion, developed by National Bio-Energy Group Co., Ltd. in Shanxian, Shandong Province, began operating and connecting to the grid in 2006 (Zhang et al., 2010), the total installed capacity of biomass power generation increased from approximately $1400 \mathrm{MW}$ in 2006 (Liu et al., 2014) to approximately 9477.10 MW in $2014^{2}$, and Chinese authorities have proposed the objectives that the installed capacity of biomass power would reach to $13000 \mathrm{MW}$ and the annual electricity output would be 78 billion $\mathrm{kW} \cdot \mathrm{h}$ by $2015^{3}$, and the installed capacity could be accumulated to $30000 \mathrm{MW}$ by $2020^{4}$. However, the real electricity output during in 2014 was 41.65 billion $\mathrm{kW} \cdot \mathrm{h}^{2}$. Thus, it can be calculated that the average capacity factor of China's biomass generating units was about $50 \%$ (41650000 MW·h/9477.10 MW/8760 h per year). Coupled with that, problems are emerging including aspects of technology, economic feasibility, and policy. Our research focuses on the latter two issues. Related to economic feasibility, critical issues include insufficient biomass feedstock supply and high costs for biomass, issues with efficient transportation and storage, and the siting of plants. On the policy side, a lack of adaptability within the feed-in tariff mechanism and related financial subsidies are considered (Liu et al., 2014, 2015; Zhao et al., 2012; Zhao and Yan, 2012).

\footnotetext{
${ }^{1}$ Data from Report of China's Renewable Energy Industry (2015) released by the China National Renewable Energy Centre (CNREC).

2 According to Data Manual of Renewable Energy (2015) released by the CNREC.

${ }^{3}$ Data from 12th Five-Year Plan for Biomass Energy Development released by the National Energy Administration in 2012.

${ }^{4}$ Data from Mid-and Long-Term Plan for Renewable Energy Development released by the National Development and Reform Commission in 2007.
} 
The available biomass feedstock in China is about 460 million tons of coal equivalent per year, of which crop residues are 200 million tons of coal equivalent ${ }^{1}$, including corn stover, rice and wheat straw, etc. And wood residues are 350 million tons (200 million tons of coal equivalent), most of which have been utilized ${ }^{1}$. Because the distribution of the forest biomass is more centralized and its production and supply system is better-developed than the agri-biomass, and what farmers' behaviors mainly affect is the supply of crop residues, we focus on the agricultural biomass in this study. Farmers are scattered across the country, and thus developing efficient supply chain is an important issue. Currently, there are two main modes of feedstock supply in China, i.e., direct-deal (direct sales between the farmer and the plant) and broker (acting as the reseller) patterns (Wei, 2014); in practice, the conditions are usually a mixture of the two. However, after the field investigation, we found that these conventional patterns were unsustainable. Because the low price of agriculture biomass leads to few farmers willing to sell crop residues; the insufficiency of biomass supply makes the power generation unable compensate costs so that the plant could not continue to procure more biomass or raise its price. It is the vicious circle in these two patterns that hinder the sustainable production of the supply chain.. Therefore, it is necessary to propose an organization that would have sufficient impact on farmers' behavior to lead to efficient operations of the feedstock supply chain.

Under the current institution in China, which is a vertical administration system, it is the villagers' committee that plays the part of administering the rural areas. As a government agent, the committee is an official organization whose influence penetrates all aspects of a farmer's life. Tan et al. (2014a) and Yu (2014) found that this organization has such a significant impact on farmers' economic behaviors that it could guide farmers at the field level on behalf of the government, especially in strengthening the willingness to supply the crop residues. During interviews and questionnaire surveys, many experts suggested that importing a villagers' committee could take full advantage of its authority and optimize the architecture of feedstock 
supply chains. A number of farmers presented the expectation of the villagers' committee's participation. Therefore, we propose a brand new supply pattern in which the villagers' committee establishes a biomass feedstock cooperative that is responsible for collection, transportation and temporary storage.

Methodologically, numbers of studies focused on modeling and optimizing the biomass feedstock supply system with the approach of supply chain simulation, which is a useful tool for providing decision supports to better deal with the complexity in the supply chain networks (Oliveira et al., 2016). First, to understand the dynamics and interactions, computer-based discrete-event simulation was widely employed, offering the flexibility to interpret system behavior when cost parameters and policies are changed (Manuj et al., 2009). Sorhansanj et al. (2006) proposed a discrete-event simulation based Integrated Biomass Supply Analysis and Logistics (IBSAL) model to simulate the collection, storage, and transport operations for supplying agricultural biomass to a biorefinery. Based on the study, Ebadian et al. (2011) developed a IBSAL-Multi Crop model to analyze a multi-agricultural logistics system for a cellulosic ethanol plant, estimating the daily biomass demand, the logistics cost and the required storage capacity. Second, for the purpose of improving the variable performance, $\mathrm{Yu}$ (2011) and $\mathrm{H}$. Wang (2014) identified the optimal facility configuration and vehicle schedule with the simulated feedstock supply/transportation system for China's biomass-based power plants. Zhang et al. (2012) built a simulation model of biomass supply chain for biofuel to support the decision-making of the optimal biofuel facility location, logistics design, inventory management, and information exchange. Third, aimed at testing new scenarios and models, Mobini et al. (2011) evaluated three harvesting methods with a simulation model based on the IBSAL framework. Windisch et al. (2013) investigated two forest biomass supply chains in different operational environments and estimated the work time expenditure with discrete-event simulations and business process mapping. In addition, Yu and Tao (2009a, 2009b, 2009c, 2008) conducted a series of studies evaluating the 
biomass-based fuel ethanol production system from perspectives of economic, energy and environment combining LCA and Monte Carlo Simulation.

With regard to the stakeholder participation pattern in the biomass feedstock supply chain, many researchers have emphasized the approach of game theory from the theoretical perspective. J. Sun et al. (2013) built a simple game model of a supply chain that consisted of one supplier and two buyers to develop optimal managerial strategies. Further, Nasiri and Zaccour (2009) proposed a more complex dynamic-game-theoretic approach with complete information in order to model the process of utilizing biomass for power generation in Canada considering three players, the distributor, the facility developer and the participating farmer. Based on that, Wang (2011) constructed two complete information dynamic game models that represented supply chains in the direct-deal and broker patterns in order to observe the impact of policy incentives on game equilibrium. Moreover, this study established a signaling game that involved a power plant and a broker and a principal-agent game that involved the government and a broker, providing the framework for analyzing the feedstock supply chain for biomass power generation under incomplete information game theory. In addition to these typical studies on the vertical relationship between the players along the biomass supply chain, a number of studies have explored the horizontal competition between the energy producer within the biomass supply chain and other industrial entities (alternative sugarcane residue users (de Oliveira Florentino and Pereira Sartori, 2003), paper mills). Overall, these studies mainly focused on the implications of government incentives (the implemented subject and the level of subsidy) on the biomass supply quantity.

Integrating the advantages of both supply chain simulation and game theory, multi-agent simulation has become a trend on the rise (Oliveira et al., 2016), ;which makes it easier and more convenient to observe the impacts of related parameters on the supply system's performance incorporating the interdependence of the strategies that players adopt. Concerning biomass supply, Shastri et al. (2011) studied the 
dynamics of a feedstock production system in Illinois in the United Sates by developing and applying an agent-based model with respect to two key stakeholders - farmers and a bio-refinery — as independent agents using a set of rules that reflected the economic, social, and personal attributes. Beck et al. (2008) used agent-based modeling tools to plan and optimize energy networks combined with a mix of global optimization, which was demonstrated for a case study of regional electricity generation in South Africa with biomass as feedstock. More generally on the supply chain as it involves farmers, Ge et al. (2015) developed an agent-based simulation model of wheat supply chain in Canada and compared its solutions and polices with those from an analytic model, and they identified effective wheat quality testing strategies. It must be noted that these studies were based on the condition in which the farm-cooperative was the basic organization form of agricultural production (Zhang et al., 2014). Especially in the United States, the widely grown energy crops are maize, soy, switchgrass, Miscanthus and pine (Del Grosso et al., 2014), resulting in strong willingness to supply and farmers' powerful control over the prices of biomass through bidding for delivery contracts (Shastri et al., 2011). Hence, specifically for China's circumstances, we develop innovations in a multi-agent model that take into account the highly scattered farmers' immaterial utility as well as the powerful influence of the villagers' committees, in order to study the effect of the policy of establishing a villagers' committee-cooperative supply pattern.

The contributions of this study are proposing a villagers' committee-cooperative feedstock supply pattern for biomass power generation and developing a multi-agent framework that is aimed specifically at China's situation. To the best of our knowledge, no study has introduced such a rural grassroots government organization into the biomass feedstock supply chain, or quantified the impact of this integration on the efficiency of the feedstock supply system. Given that the major feedstock of China's biomass energy is agricultural residue, dispersed farmers prefer to discard or even incinerate their residues in the field, which leads to severe air contamination, 
rather than supply them to plants that are operating under sophisticated management at the high cost of labor, machinery and transport. Because the infrastructure in rural areas is relatively laggard, the farmers pay more attention to the improvement of public facilities and welfares. Hence, according to these different social and economic attributes and behaviors, the agent-based model is modified and innovated to compare the villagers' committee-cooperative supply patterns with the conventional ones. Furthermore, this model is applied in order to explore the factors that affect the performance of the new pattern.

This paper is structured as follows. The next section describes the multi-agent modeling and simulation of two conventional feedstock supply patterns and the new villagers' committee-cooperative pattern. Section 3 presents the simulation results with the comparison of these three patterns, and it conducts the sensitivity analysis. The final section summarizes the work, draws important conclusions, and presents future research plans.

\section{Methods}

\subsection{Model Framework}

Agent-based modeling, particularly multi-agent simulation, is a technology that was established on the theory of complex adaptive systems (CASs), whose units have the characteristics of autonomy, social ability, reactivity and pro-activeness (Chaib-draa and Müller, 2006). The core of this technique is the concept of the intelligent agent - the abstraction of individuals who operate in socioeconomic systems in order to be represented on computer platforms. Today, a number of multi-agent simulation libraries and toolkits have been developed including NetLogo, StarLogo, Swarm, MASON, Ascape, EcoLab, as well as RePast (North et al., 2013), which this research employs.

The objectives of this multi-agent model are (1) to model and research the operation mechanism of the feedstock supply chain with the existence of multiple agents and compare the performance of the two conventional supply patterns 
(direct-deal and broker patterns) with the villagers' committee-cooperative mode that we propose; (2) to observe and analyze the impacts of internal and external parameters on the efficiency and sustainability of a supply chain, especially for the villagers' committee-cooperative pattern.

To achieve these goals, the first important step is to identify the key stakeholders in the supply chain for biomass generation, i.e., the multiple agents that we model. Unlike the United States or European countries, China's biomass generation supply chain is still at the preliminary stage, and thus, no mature, dedicated feedstock supply system has been developed. Hence, except for farm consultants, custom harvesters and storage elevators, the key stakeholders in this model are biomass plants, farmers, brokers, and the villagers' committee-cooperatives that the new supply pattern involves. Each holder acts as an independent decision-maker who is modeled as an intelligent agent in the simulation and who is equipped with abstract attributes and behavior methods. The important stakeholders and their roles in the feedstock supply system are generally described as follows:

(1) Plant: sets the purchase price; produces power, heat and/or bio-products with biomass feedstock.

(2) Farmer: harvests, collects and in-field transports the biomass.

(3) Broker: purchases the biomass from scattered farmers; delivers it to the plant using road transportation.

(4) Villagers' committee-cooperative: organizes farmers to harvest the biomass; provides public welfares and improves public facilities.

It is necessary to note that we internalize the role of the third-party logistics provider (road transportation) into the plant, broker and villagers' committee-cooperative, represented as their private cost, and the plant is provided with an optimal site without involving distributed depots.

Because comparing three supply modes under which agents' behaviors are not quite the same is one objective of this study, the following sections define patterns and 
then give a comprehensive description of different agents and, finally, the study model's computer implementation.

\subsection{Patterns}

Fig. 1 demonstrates the architectures of feedstock supply chains under the three patterns. This study assumes that in each supply mode, there is only one biomass plant and only one biomass feedstock utilization path, i.e., there is no competition among the plants or the ways of utilizing biomass.

Figure 1 here.

\section{Pattern 1: Direct-Deal Pattern}

Under this pattern, famers who possess the biomass contact the biomass plant directly, through collection, storage and transportation, to transfer the feedstock from the field to the generator. For convenience, it is assumed that the plant is responsible for offering the purchase price, the road transportation and warehousing and that farmers decide whether to accept the price offered by the plant or not according to their own condition, i.e., whether to supply the biomass to the plant and then take charge of collecting the biomass, in-field transportation and storage.

\section{Pattern 2: Broker Pattern}

The broker serves as an intermediary between the farmer and the plant in this pattern. After the biomass is harvested, the brokers aim to purchase the feedstock from farmers door to door and then sell it to the plant. During the process, the broker also undertakes the jobs of preprocessing (bundling, compression, etc.) and decentralized storage. This supply mode avoids the uncertainty and high cost caused by the plants' directly working with any number of scattered farmers.

Patterns 1 and 2, the two conventional models, are commonly used in China.

Pattern 3: Villagers' Committee-Cooperative Pattern

In this paper, we pioneer the villagers' committee-cooperative pattern, in which a formal, official villagers' committee is integrated into the feedstock supply chain. Compared with the two conventional patterns above, the feature of this pattern is a 
new type of cooperative organized by villagers' committees.

A cooperative is a socioeconomic organization with attributes of enterprise and community $(\mathrm{Xu}, 2012)$. Its primary goals are to promote higher income for its members, enhance group access to capital and new technology and to help lower production and marketing costs (Zheng et al., 2012). Based on these functions, cooperatives can be grouped into production, related service, circulation and credit cooperatives. The biomass feedstock supply cooperative we discuss here is actually a type of agricultural production cooperative. Collectivization programs, in the forms of voluntary and then compulsory cooperation (people's commune), were implemented in China from 1952 to 1978 , still a sensitive and significant issue in Chinese political and economic history. Although it gained some early success, the movement eventually damaged the rural economy and agricultural productivity because it constrained individual choice and muzzled the economic incentives needed for efficient agricultural production and markets, resulting in the de-collectivization and household responsibility system during the period of reform and opening-up (Zheng et al., 2012). However, the rural districts witnessed some transformations in the last two decades in that a large number of young people became urban migrant workers, children were left behind with the elderly, and both the infrastructure and the public facilities were extremely backward. In order to guarantee domestic food security and promote the agriculture sector, the Farmers' Professional Cooperatives Law came into effect in 2007, and tax incentives and financial grant support were promulgated. By the end of April 2015, more than 1.37 million farmers' cooperatives have been registered in China 5 .

A number of biomass feedstock supply cooperatives have arisen in provinces abundant in bio-resources (Wang, 2009). The existing biomass supply cooperatives are economic organizations built spontaneously by farmers, who collaborate to collect

\footnotetext{
5 According to Suggestion on Further Promoting the Sound Development of Farmers' Specialized Cooperatives released by the Ministry of Agriculture in 2015.
} 
and transport the biomass, and jointly invest to buy machines and vehicles. We find no comprehensive data on China's biomass supply cooperatives. According to relative news reports, cooperatives specialized in supplying biomass to plants or bio-refineries have emerged in provinces of Jiangsu, Hunan, Sichuan (Mei and Lou, 2014; Tao, 2011; Zhou, 2012), etc. 56 straw cooperatives, involving 1517 households of farmers, have been established in Yancheng City of Jiangsu Province, which could annually collect and sell more than 400 thousand tons of straw. It's reported that a cooperative with 100 members could averagely deliver about 15 to 20 thousand tons of crop residues per year, with the price of 200-300 CNY/t (Mei and Lou, 2014; Tao, 2011). Our investigation found that the cooperation decreases about $50 \%$ of feedstock cost with simplified intermediate links, preferential policies and subsidies. And farmers have more powerful status in the negotiation with plants so that the market and the price could be guaranteed. However, the existing cooperatives have not thoroughly reversed the situation of insufficient feedstock supply and deficient participating enthusiasm. According to our investigation, the average coverage radius of one cooperative is about $2-3 \mathrm{~km}$, and less than $10 \%$ of villagers have joined the cooperatives. It's required a large initial investment, about 500-1000 thousand CNY, in machines and vehicles for each cooperative. As an economic organization, the biomass cooperative only harvests the biomass convenient to be collected, and most of crop residues are still abandoned in the field.

Considering the administration system of most rural areas in China, the biomass feedstock collecting cooperative we design is led by a villagers' committee, which is a basic mass autonomous organization with Chinese characteristics. This formal organization has such a significant impact on farmers' economic behaviors (Tan et al., 2014a) that it can guide the farmers at the micro level on behalf of the government. In addition, the committee plays the dual role as an agent of both villagers and the government under the current institution. Thus, the villagers' committees bear the responsibilities of administrative management as well as providing public welfares 
(Gao and Zuo, 2011). Hence, a foundation is meant to be established by the committee in proportion with revenue earned from the sale of biomass in order to improve the local infrastructure, which is expected to enhance the farmers' enthusiasm for supplying biomass feedstock.

In summary, the difference between our new cooperative model and the existing cooperatives is that we introduce the official organization, villagers' committee, into the cooperative. And the revenue is used to improve local public facilities and provide better public welfares. In Pattern 3 farmers are organized by a biomass feedstock supply cooperative led by villagers' committee to collect the biomass after harvest season, and the cooperative is responsible for preprocessing, in-field and road transportation and temporary storage by providing machinery and vehicles and eventually delivering the biomass feedstock to plants under long-term agreements. With regard to profit, except for the part that is divided among members according to their supply of biomass, the profits are invested in maintaining and improving the local public facilities. It must be noted that introducing the villagers' committee is not for the purpose of forcing the farmers to supply feedstock by administrative order but to hire staff in the form of a cooperative to collect the biomass while giving full play to its influence. The revenue from delivering feedstock could ensure that staff are paid, and the remainder can be used for public welfares in the village. Considering the expectation of immaterial utility, this pattern could motivate farmers to supply feedstock.

\subsection{Agents}

The stakeholders described in Section 2.1 are identified as the intelligent agents that we model in the multi-agent simulation. The reliability of simulation studies relies on whether the agents in the model precisely represent the characteristics of individuals or entities in the real world. At the same time, an excessively detailed model will bring about excess computation complexity, which is not time-efficient. Thus, we balance between the two by capturing the important social and economic 
aspects that affect the supply chain in order to mathematically describe the agents.

Multi-agent simulation depends on object-oriented programming (OOP) to a large extent. Accordingly, each category of agents who have common attributes and decision-making rules is programmed as a class; and each concrete agent is an object (instant) of the class, which is the realization of the abstract class (Larkin and Wilson, 1995). Hence, the agent modeling is actually a mathematical description of OOP language.

\section{Plant}

The biomass power plant is the kernel agent in the feedstock supply chain simulation model; its production operates by setting the biomass purchase price, seeking supply sources (farmers or intermediaries) for sufficient feedstock, and generating and supplying power (and heat) to the grid. Its objective is maximizing the profits with revenue from the sale of electricity against all categories of cost (feedstock and operation here), which can be presented as Eq. (1):

$$
\max _{p_{\mathrm{P}}>0} \pi_{\mathrm{P}}=p_{\mathrm{e}} \eta Q-p_{\mathrm{P}} Q-c_{\mathrm{p}} Q
$$

where $p_{\mathrm{p}}$ is the purchase price offered by plant $(\mathrm{CNY}) ; \pi_{\mathrm{P}}$ is the plant's profit of this round; $p_{\mathrm{e}}$ is the biomass power feed-in tariff set by the authorities (the current level is $0.75 \mathrm{CNY} / \mathrm{kW} \cdot \mathrm{h}$ ) (Zhao and Yan, 2012); $\eta$ is the conversion ratio of biomass material to electricity $(\mathrm{kW} \cdot \mathrm{h} / \mathrm{t}) ; Q$ is the amount of biomass $(\mathrm{t})$ purchased from farmers (Pattern 1, $Q=\sum_{i=1}^{N} Q_{i}$ ), brokers or cooperatives (Patterns 2 or 3, $Q=\sum_{j=1}^{M} Q_{j}$, where $N$ is the number of local farmers and $Q_{i}$ is the biomass supply amount of farmer $i ; Q_{i}=0$ when the farmer has no willingness to supply, $M$ is the number of local brokers or cooperatives, $Q_{j}$ is the biomass supply amount of the broker or cooperative $j$ ); and $c_{\mathrm{p}}$ is the operation cost per unit of biomass feedstock 
(CNY/t), including freight, storage cost, material cost and water fee, depreciation cost, maintenance cost, administration expense, and finance charge, etc.

In order to seek the appropriate purchase price $p_{\mathrm{p}}$ to realize the maximum profit $\pi_{\mathrm{P} \max }$, the plant agent employs the approach of feedback regulation to constantly adjust $p_{\mathrm{p}}$ (Fig. 2), where $t$ is the sequence number of trading rounds. When adjustment range $\Delta p$ is less than certain, the purchase price $p_{\mathrm{p}}$ tends to be stable.

Figure 2 here.

\section{Farmer}

Each farmer is defined as an object of the farmer class, which is noted as farmer $i$ (in Pattern 1) or farmer ji (in Patterns 2 and 3) here. A farmer agent's attributes include the amount of biomass that he possesses, the unit cost in collection and the opportunity cost, and his main behavior is deciding whether to collect and sell the biomass. In this study, the objective of the farmer agent is to maximize his utility (Eq. (2), (6) \& (10)); that is, if the utility from selling biomass feedstock is great, the farmer will supply all of the biomass he possesses; otherwise, the biomass will be discarded (Eq. (4), (8) \& (12)). Considering the different details of the three patterns, the forms of utility and related functions are differentiated (Table 1). It must be noted that in Pattern 3, the utility of participating in biomass supply cooperation is derived not only from the expected profit from the farmers' selling his biomass and the subsidy but also from the rural infrastructure and public service that the cooperative helps to provide (Eq. (10)).

Table 1 here.

where $u_{\mathrm{F}_{i}}$ or $u_{\mathrm{F}_{j i}}$ is the utility that the farmer gains in this trading round; $c_{\mathrm{F}_{i}, 1}$ or $c_{\mathrm{F}_{j i}, 1}$ is the collection cost coefficient; $c_{\mathrm{F}_{i}, 2}$ or $c_{\mathrm{F}_{j i}, 2}$ is the opportunity cost, meaning the maximum revenue the farmer could earn in alternative ways given the time and 
labor he spends in collecting and selling the biomass feedstock $(\mathrm{CNY}) ; \pi_{\mathrm{F}_{i}}$ or $\pi_{\mathrm{F}_{j i}}$ is the actual profit from selling the biomass $(\mathrm{CNY}) ; \pi_{\mathrm{E}, \mathrm{F}_{i}}$ or $\pi_{\mathrm{E}, \mathrm{F}_{\mathrm{j} i}}$ is the expected profit $(\mathrm{CNY}) ; s$ is the subsidy per unit of biomass $(\mathrm{CNY} / \mathrm{t}) ; q_{i}$ or $q_{j i}$ is the amount of biomass that the farmer possesses (t); $Q_{i}$ or $Q_{j i}$ is the amount of biomass that he supplies, which equals 0 when the farmer is not willing to deliver $(\mathrm{t})$; $\omega_{\mathrm{F}_{j i}}$ is the weight that farmer $j i$ puts on the public welfares from the cooperative; $\gamma_{j}$ is the percentage according to which the cooperative divides the revenue to provide public service; and $\pi_{\mathrm{C}_{j}}$ is the profit from the villagers' committee-cooperative that the farmer belongs to (CNY).

\section{Broker}

The broker agent is an intermediary who gathers the biomass from farmers to resell it for biomass power generation, obtaining the margin in between. His profit function is presented as Eq. (14):

$$
\pi_{\mathrm{B}_{j}}=p_{\mathrm{P}} Q_{j}-p_{\mathrm{B}_{j}} Q_{j}-c_{\mathrm{B}_{j}} Q_{j}
$$

where $\pi_{\mathrm{B}_{j}}$ is the profit that broker $j$ earns from reselling the biomass to plants excluding the cost (CNY); $Q_{j}$ is the amount of biomass feedstock he purchases from farmers, which is subject to $Q_{j}=\sum_{i=1}^{N_{j}} Q_{j i}$ (t) where $N_{j}$ is the number of farmers who sell biomass to him; $p_{\mathrm{B}_{j}}$ is the price of purchasing feedstock from farmers $(\mathrm{CNY} / \mathrm{t})$; and $c_{\mathrm{B}_{j}}$ is the unit cost $(\mathrm{CNY} / \mathrm{t})$.

Broker $j$ 's main behavior is offering his purchase price according to his expected profit, which is subject to $\lambda_{j}=\frac{\pi_{\mathrm{B}_{j}}}{p_{\mathrm{P}} Q_{j}}$. Here, the expected profit rate $\lambda_{j}$ is an attribute of the broker agent and is set as static, and we incorporate the dynamic 
situation in additional research in which the broker learns to adjust his profit according to the internal and external environments.

\section{Villagers' Committee-Cooperative}

The villagers' committee-cooperative agent is important in the research for a comparison study. First, farmers are organized under a cooperative that is led by the local villagers' committee. This system avoids an excess of scattered farmers (Pattern 1) who work directly with the plant, which is similar to the role of brokers (Pattern 2). Second, the cooperative is not aimed at earning the margin in between that the brokers depend on but on increasing the farmers' income and utility. As the source of the welfare foundation, the cooperative's profit is calculated as Eq. (15):

$$
\pi_{\mathrm{C}_{j}}=p_{\mathrm{P}} Q_{j}-c_{\mathrm{C}_{j}} Q_{j}-\sum_{i=1}^{N_{j}} \frac{2}{3} c_{F_{j i}} Q_{j i}^{\frac{3}{2}}
$$

where $Q_{j}$ is the total amount of biomass that the cooperative member supplies (t) subject to $Q_{j}=\sum_{i=1}^{N_{j}} Q_{j i}$ and $c_{\mathrm{C}_{j}}$ is the unit cost $(\mathrm{CNY} / \mathrm{t})$. The last term of the equation, $\sum_{i=1}^{N_{j}} \frac{2}{3} c_{F_{j i}} Q_{j i}^{\frac{3}{2}}$, is the sum of the in-field transportation cost.

Please note that when the farmers are deciding whether to supply the biomass feedstock in a given trading round, the cooperative's profit $\pi_{\mathrm{C}_{j}}$ and the total amount of biomass $Q_{j}$ are unknown, and both are calculated according to the supply of farmers. Hence, programming the farmer agent in Pattern 3 incorporates the technique of Cournot learning, in which the expected utility $u_{\mathrm{E}, \mathrm{F}_{j i}}$ depends on the cooperative's profit and total amount of biomass in the previous round (Eq. (16)):

$$
u_{\mathrm{E}, \mathrm{F}_{j i}}=\max \left\{\ln c_{\mathrm{F}_{j i}, 2}, \ln \pi_{\mathrm{E}, \mathrm{F}_{j i}}+\omega_{\mathrm{F}_{j i}} \ln \gamma_{j} \pi_{\mathrm{C}_{j}}^{(t-1)}\right\}
$$

In the initial round, the total supply amount equals $40 \%$ of the sum of feedstock that farmers possess, i.e., $Q_{j}^{(0)}=40 \% \times \sum_{i=1}^{N_{j}} q_{j i}$; in these circumstances, the stable participation 
rate of farmers in Patterns 1 and 2 was approximately $40 \%$ when we pre-simulated.

\subsection{Simulation Schedule}

Operating a biomass feedstock supply chain consists of a number of trading rounds in a dynamic and continuous process. The full simulation sequence is the realization of this course, which we called the schedule in the OOP. For the convenience of simulation, we assumed that in each round, related agents would take actions sequentially (Fig. 3). The numbers above the arrow are the priorities of an agent's behaviors; the larger the number, the earlier the agent acts. Corresponding to these priorities, the positive agents and their actions are presented in Table 2.

Figure 3 here.

Table 2 here.

For consistency in the comparison research, the numbers of brokers and cooperative agents are assumed to be equal, so that they share the same index $j$ $(j=1,2, \ldots, M)$, and the supply chains in each of the three patterns would operate simultaneously after the simulation began. In addition, the profit rate, participation rate and average utility of farmers are calculated as the performance indicators when each round is complete.

\section{Application and Results}

\subsection{Model Application}

REcursive Porous Agent Simulation Toolkit (RePast; Argonne National Laboratory; Argonne, Illinois, USA) was used for the simulation; RePast is a free and open-source simulation environment for agent-based modeling. It was originally developed by Sallach, Collier, and others at the University of Chicago in 2000, and it was subsequently expanded by the Argonne National Laboratory as a reusable software infrastructure that could support "rapid social science discovery" based on extensive computational experimentation. Successive releases of RePast have extended the system to manage large-scale agent simulation application development. 
The most recent version, RePast Simphony 2.3.1, was released on June 1, 2015. Users have applied it to a wide variety of applications that range from social systems to evolutionary systems, market modeling, and industry analysis (North et al., 2013). Compared with other simulation environments such as NetLogo and Swarm, RePast has the advantages of a wide set of libraries for developing models and being designed specifically for social science application (Robertson, 2005).

Multi-modular structures are employed by the simulation toolkit. We utilized some of the core plug-ins in this study: the time schedule (the scheduler) which is described in 2.4, and space management, specifically, context and random number generation. Contexts are hierarchically nested and named containers that hold model components, which are typically agent objects (Fig. 4). With the functions of RePast, we were able to generate agents and/or agent groups, configure and modify their parameters, and observe their interaction with each other using the simulation interface.

Figure 4 here.

Table 3 and Table 4 show the configurations of the context and agent parameters, and the data are from the survey we conducted and the relevant literature. The model considers the agricultural residue — straw — as the major feedstock of the biomass power generation. Due to China's vast territory and the diversity of crops, the simulation focuses on the circumstances in North China, where the main straw sources are crops of wheat, corn and cotton.

Table 3 here.

Table 4 here.

For the context, because there is no supply pattern that is incorporated in the cooperative led by the villagers' committee, the simulation generates 500 farmers $(N)$ and 10 brokers/villagers' committee-cooperatives $(M)$, assuming that every broker or cooperative will interact with 50 farmers $\left(N_{j}\right)$ without considering the competition between brokers and cooperatives. The feed-in tariff of biomass power $p_{\mathrm{e}}$ is 0.75 
$\mathrm{CNY} / \mathrm{kW} \cdot \mathrm{h}$ according to the document "Notice on Improvement of Power Pricing Policy for Agriculture and Forestry Biomass Generated”, released by the National Development and Reform Commission of China in July 2010 (Zhao and Yan, 2012). We initially configured the subsidy per unit of biomass $s$ as $0 \mathrm{CNY} / \mathrm{t}$ in the pattern comparison study. As the external parameters, $p_{\mathrm{e}}$ and $s$ have significant impacts on the feedstock supply chain for biomass power generation, which will be researched in the following Discussion section (Section 3.3) with the modification of their values.

As with the plant agent, the feedstock consumption for biomass plants of $30 \mathrm{MW}$ in China is approximately $1.2 \sim 1.67 \mathrm{~kg} / \mathrm{kW} \cdot \mathrm{h}$ (Hao, 2008; Wang, 2011; Zhao and Yan, 2012); hence, the conversion ratio of biomass material to electricity in the simulation $\eta$ is set as $650 \mathrm{~kW} \cdot \mathrm{h} / \mathrm{t}$. Tan et al. (2014b) determined that the fuel collection cost could be as much as 277.6 CNY/t, and the transportation costs could account for approximately $43 \%$ of the total cost. The initial offer for the biomass purchase price was assumed to be $300 \mathrm{CNY} / \mathrm{t}$. After repeated testing, we selected $\pm 5 \mathrm{CNY} / \mathrm{t}$ as the initial adjustment range of the price offer. As the simulation progressed, the range shrank by $80 \%$. Generally speaking, it would take more time to reach a stable offering price with a smaller initial adjustment range. Otherwise, if the magnitude were too large, it would be so early that it would tend to be stable and we would not be able to observe the entire course of plant's movement. Moreover, because the operation cost per unit of electric production was approximately $0.23 \mathrm{CNY} / \mathrm{kW} \cdot \mathrm{h}$ in our investigation, the operation cost per unit of feedstock $c_{\mathrm{P}}$ is estimated as $160 \mathrm{CNY} / \mathrm{t}$ in Pattern 1. Given that the road transportation is transferred to brokers and cooperatives in Patterns 2 and 3, this cost coefficient is decreased to $50 \mathrm{CNY} / \mathrm{t}$ due to approximately $110 \mathrm{CNY} / \mathrm{t}$ of transportation cost estimated by Tan et al. (2014b).

With regard to the farmer agent's collection cost coefficient $c_{\mathrm{F}_{i}, 1}\left(c_{\mathrm{F}_{j i}, 1}\right)$, opportunity cost $c_{\mathrm{F}_{i}, 2}\left(c_{\mathrm{F}_{j i}, 2}\right)$ and ownership of biomass $q_{i}\left(q_{j i}\right)$, due to the stochastic nature of these parameters, a normal distribution function is considered for 
each one in the simulations, in addition to the broker agent's unit $\operatorname{cost} c_{\mathrm{B}_{j}}$, the villagers' committee-cooperative agent's unit cost $c_{\mathrm{C}_{j}}$ and the profit-dividing proportion for public welfare foundation $\gamma_{j}$; most of the distribution data for these variables were acquired from the survey that we conducted. According to the relevant year 2014 statistics that were released by China's National Bureau of Statistics, the rural average labor per household was 2.8 , and the rural net income per capita was $9892 \mathrm{CNY}$. A farmer spent an average of 3 days collecting his biomass. Thus, the mean of opportunity cost $c_{\mathrm{F}_{i}, 2}\left(c_{\mathrm{F}_{j i}, 2}\right)$ is estimated to be $250 \mathrm{CNY}$ $(98982 \mathrm{CNY} \times 2.8 \div 365 \times 3 \approx 250 \mathrm{CNY})$.

According to the data on the existing biomass supply cooperatives, parameters in the new villagers' committee-cooperative pattern is assumed as follows: (1) because the cooperative would unite farmers to collect the biomass and farmers themselves would not have to consider the problems of temporary storage and renting bundling machines and transport vehicles, the mean collection cost coefficient $\bar{c}_{\mathrm{F}_{i}, 1} \quad\left(\bar{c}_{\mathrm{F}_{j i}, 1}\right)$ in Pattern 3 is assumed to be $60,40 \%$ of that in Patterns 1 and 2; (2) the mean weight with which the farmer agent views the public welfare provided by the villagers' committee-cooperative $\omega_{j i}$ is estimated at 0.05 ; (3) Our investigation on the existing cooperatives found that the mean unit cost $\bar{c}_{\mathrm{C}_{j}}$ was about $40 \mathrm{CNY} / \mathrm{t}$, and about $20 \%$ of the revenue was used to pay for members' insurances, which is assumed as the mean proportion of public welfare foundation $\overline{\gamma_{j}}$. For these estimates, including the opportunity cost $c_{\mathrm{F}_{i}, 2}\left(c_{\mathrm{F}_{j i}, 2}\right)$, their impacts on the feedstock supply chain in Pattern 3 will be explored later in the Discussion section (Section 3.3). Additionally, owing to the competition between brokers who are not considered, the broker agent's profit rate $\lambda_{j}$ is constantly set to be $10 \%$.

\subsection{The Empirical Results and Analysis}


Table 5 and Fig. 5-8 present the simulation results, including the comparison of the three supply patterns and the profiles of the plant's profit and profit rate, the farmers' participation rate, the biomass supply and the price. After multiple re-simulations, we found that it took approximately 30 rounds for the supply chain to stabilize, especially for farmers' participation rate and biomass supply in Pattern 2 (Fig. 7). We compared the three supply patterns from the aspects of profiles of the plant's profit, the farmers' participation, the biomass supply and the price. Because the simulation context was hypothetical and consisted of only 500 farmers, the supply of biomass is plotted in terms of the percentage of the gross biomass amount farmers possessed.

Table 5 and Fig. 5 show the performances of the three patterns, i.e., the stable values of the plant's profit and profit rate, the farmers' participation rate, the biomass supply and the price. Here, "stable" means that equilibrium in the evolutionary game has been attained, that is, a state in which the strategies of all players are mutually optimal so that everyone will not change their actions to prevent losses.

Table 5 here.

Figure 5 here.

The most important observation is that the four aspects of Pattern 3 are superior to those in Patterns 1 and 2. Plant profits for Pattern 3 are 98990 CNY over 17447 $\mathrm{CNY}$ and $34123 \mathrm{CNY}$, the profit rate is $32 \%$ over $11 \%$ and $18 \%$, the farmers' participation rate is $76 \%$ over $35 \%$ and $45 \%$, and the supply amount $84 \%$ over $42 \%$ and 52\%. Pattern 3 shows respective increases of $467 \%$ and $190 \%$ in plant's profit, $182 \%$ and $81 \%$ in plant's profit rate, $120 \%$ and $8 \%$ in farmers' participation rate, and $101 \%$ and $60 \%$ in biomass supply amount, which are significant. With the biomass price, Pattern 3 is at the same level with Pattern 1, which is lower than that of Pattern 2.

The advance in the plant's profit rate is because of the lower stable biomass price $p_{\mathrm{P}}$ (Fig. 8) and unit operation cost $c_{\mathrm{P}}$ (Eq. (17)): 


$$
\lambda_{\mathrm{P}}=\frac{p_{\mathrm{e}} \eta Q-p_{\mathrm{P}} Q-c_{\mathrm{P}} Q}{p_{\mathrm{e}} \eta Q}=1-\frac{p_{\mathrm{P}}+c_{\mathrm{P}}}{p_{\mathrm{e}} \eta}
$$

where $\lambda_{\mathrm{P}}$ is the plant's profit rate. For plant's profit, its improvement is because the biomass supply amount in Pattern 3 increases with the decrease of its biomass purchase price and operation cost because the plant's margin is in direct proportion to the biomass supply and in inverse proportion to the biomass purchase price and the operating cost (Eq. (1)). Furthermore, the reduced stable biomass price is actually due to the disintermediation in Pattern 3, which eliminates marginalization by the intermediaries, that is, the brokers (Fig. 1). At the same time, the villagers' committee-cooperative pattern groups the farmers as a single entity that works directly with the plant, which diminishes the plant's unit operation cost. The increase in the biomass supply amount results from the increase of utility that farmers could attain from supplying biomass, which is attributable to the lower collection cost and immaterial utility brought by the cooperative (Eq. (10)). This is also the factor that increases the farmers' participation rate in the supply chain, the changing profile of which is accordance with that of biomass supply (Fig. 7).

Figure 6 here.

Figure 7 here.

Figure 8 here.

\subsection{Discussion}

The results of the pattern comparison show one of a number of possibilities that could be realized in the future. Because it is discussed above that some of the parameters are estimated (Section 3.1) and the feedstock supply chain itself features a number of uncertainties, it is necessary to simulate a variety of possible scenarios in order to acquire a comprehensive understanding of the system. The following sections present the results for the impacts of specific parameters.

\section{Impact of Feed-in Tariff $p_{\mathrm{e}}$ and Subsidy $s$}

In the pattern comparison study, we assume the subsidy per unit of biomass is 0 
$\mathrm{CNY} / \mathrm{t}$, which is the common scenario in China. Because related studies have suggested that direct subsidies to farmers might stimulate their enthusiasm for supplying biomass, we conduct a scenario simulation and analysis of the impact of subsidies on the biomass supply chain, with the direct incentive to plants, the preferential feed-in tariff. Table 6 shows the plant's profits and biomass supply amounts in different scenarios, each corresponding to a combination of feed-in tariffs and subsidies, which is presented in the left three columns. Scenario 1 (preferential feed-in tariff only) was our base simulation situation, with the current biomass power feed-in tariff of $0.75 \mathrm{CNY} / \mathrm{kWh}$ and a subsidy of $0 \mathrm{CNY} / \mathrm{t}$; Scenario 2 (subsidy only) was configured with the feed-in tariff of $0.40 \mathrm{CNY} / \mathrm{kWh}$ (the average level of thermal power in China) and a subsidy of $60 \mathrm{CNY} / \mathrm{t}$ (20\% of the biomass price); Scenario 3 (preferential feed-in tariff and subsidy) has a feed-in tariff of $0.75 \mathrm{CNY} / \mathrm{kW} \cdot \mathrm{h}$ and a subsidy of $60 \mathrm{CNY} / \mathrm{t}$.

From the perspectives of plant's profit and biomass supply amount, Scenario 3 is superior to the other two, and Scenario 1 outperforms Scenario 2. Hence, the preferential feed-in tariff is still necessary considering the circumstance that the unit cost of the biomass plant is higher than that of conventional thermal and hydro power. Because the biomass plant serves as the downstream firm that has the pulling force for developing the feedstock supply chain, its profitability determines the system's operation. It is necessary to note that without subsidies, the plant profit and biomass supply amount in Pattern 3 (Scenario 1) are higher than those in Patterns 1 and 2 with the subsidy (Scenario 3). This is illustrated in Fig. 9 and Fig. 10, in which the cures of Pattern 3 in Scenario 1 both exceed those of Patterns 1 and 2 in Scenario 3.

Table 6 here.

Figure 9 here.

Figure 10 here.

Fig. 11 shows the stable plant's profit and biomass supply in the three patterns at different subsidy levels. The result illustrates the impact of the subsidy on the system's final state. Specifically, the stable plant's profit and biomass supply generally decrease 
with the reduction of the subsidy, but the biomass supply in Pattern 3 decreases less than that it does in the other two patterns, which demonstrates that the villagers' committee-cooperative pattern is able to ease the government's burden of subsidies by reshaping organization architecture between the villagers' committee and the farmers in producing biomass power.

Figure 11 here.

\section{Impact of Farmer's Opportunity Cost $c_{\mathrm{F}_{i}, 2}\left(c_{\mathrm{F}_{i j}, 2}\right)$}

It is noted above that when a farmer decides whether to sell biomass, he compares his expected utility from supplying the biomass and discarding it to do other things. Because the opportunity cost represents the maximum revenue the farmer could earn from alternative uses of his time and labor spent collecting and selling the biomass feedstock, this cost is an important influence on farmers' behaviors and the operation of the entire supply chain. Because we assume the base case to be $250 \mathrm{CNY}$, the additional scenarios are $100 \mathrm{CNY}, 150 \mathrm{CNY}, 200 \mathrm{CNY}, 300 \mathrm{CNY}$ and $350 \mathrm{CNY}$. Fig. 12 shows the stable plant profits and biomass supplies in the three patterns with different mean opportunity costs. As we can see, both decline as the opportunity cost increases. Generally speaking, the opportunity cost mainly depends on the local economy, such that higher developing increases employment opportunities and the income earned from other jobs, and therefore increases opportunity costs. However, the opportunity costs cannot reflect that the conditions in the biomass power industry would be superior with less economic development, which is the opposite case, because the development of this industry depends on a number of different factors such as the geographic region, enrichment of biomass, and farmers' attitudes and education.

Figure 12 here.

\section{Impact of Public Welfare Weight $\omega_{\mathrm{F}_{j i}}$}

In Pattern 3, the farmer puts a certain weight on the immaterial utility, i.e., public welfares in this study. The base case scenario assumes the mean of that weight is 0.05 , 
which is not based on a rigorous survey. It is, hence, important to understand the impact of this assumption on the model simulation results. Therefore, different scenarios of Pattern 3 are simulated in which the base mean public welfare weight increases to 0.25 in units of 0.05 . Fig. 13 shows the results for these simulations. It is clearly evident from the two plots that greater public welfares lead to more profit for the plant and larger biomass supply amounts. The human's weight on the immaterial utility depends on the farmers' education and age to a large extend. Hence, promoting education in rural areas has positive meaning for the biomass generation industry.

Figure 13 here.

\section{Impact of the Public Welfare Foundation Percentage $\gamma_{j}$}

One feature of Pattern 3 is the foundation that it establishes to help provide public welfares for villagers. The base case considers that $20 \%$ of the cooperative's margin is invested in the foundation in each trading round. Different scenarios of Pattern 3 are simulated in which the percentage levels vary from $10 \%$ to $30 \%$ in increments of 5\%. Fig. 14 shows the stable profits of the plant and the biomass supply at different foundation percentage levels. It can be observed that higher proportions lead to lower plant profits, but for the biomass supply amount, the figure presents the profile of first an upward and then a downward trend. This result comes about because the utility to the farmer consists of two parts that are brought about by the direct income from selling biomass and the public service provided by the foundation (Eq. (10)). Additionally, these two parts have opposite quantitative relationships with the foundation percentage. Hence, in order to improve farmers' willingness to supply biomass, an appropriate foundation percentage must be determined.

Figure 14 here.

\section{Conclusion and Policy Implications}

Chinese government pledges emissions will peak around 2030, and intends to increase the non-fossil fuels share in the primary energy consumption to around 20 
percent (M. Wang, 2014), so that various types of renewable energies have been well developed, including the biomass energy which is viewed as carbon neutral. Power generation is an environmentally friendly utilization pathway of the biomass energy. China has the enormous potential of biomass generation due to the abundance biomass resources. A series of policies and goals have been proposed to stimulate the growth of biomass power industry. However, in the year of 2014, the real capacity factor is about 50\%. And there are large gaps between targets and actual situations, especially in the annual electricity output. This technological condition leads to the state of meager profit or deficit of China's biomass plants. A main reason for the inferiority is the difficulty of feedstock collection owing to the decentralized farming model and the small-scaled self-supporting economy in China's rural districts. Previous studies have focused on this issue, and several of them involved with the government, which consistently reached an agreement on the importance of the government's support to the biomass generation industry. But those studies just mentioned raising subsidies, and the specific ways of government's intervention were not clearly identified. Hence, this study takes into consideration the particularity of China's administration and concretizes the role of government. We propose a cooperation supply pattern that incorporates the villagers' committees, i.e. to introduce the committee, which organizes specialized staff to collect the biomass, into the supply chain. And a multi-agent model framework for China's biomass feedstock supply chain is developed. The model is applied to simulate the operation of this new pattern as well as two conventional supply modes, and then various scenarios are studied to understand the impact of different model parameters on the supply chain's performance.

The results confirm that the proposed villagers' committee-cooperative pattern has advantages over the conventional patterns, direct-deal and broker patterns. The advances are that this pattern (1) increases the biomass plant's profits; (2) prevents the brokers who are individuals rather than enterprises (which results in flimsy contracts), 
from driving up biomass prices for their own benefit; (3) leads to greater supplies and farmers' participation. Furthermore, the conclusion can be reached based on the additional scenarios that higher feed-in tariff could bring about more biomass feedstock supply and higher profits for biomass plants. The cooperation supply pattern still outperforms even with low farmer subsidy amounts. Additionally, lower farmers' opportunity costs for supplying biomass, stronger their perception of immaterial utility and a reasonable cooperative's financial resource scheme can lead to the superior performance of the new pattern.

The above conclusions indicate that, to promote the sustainable development in China's biomass power industry, following four measures should be implemented:

Firstly, the rural grassroots government organization--villagers' committee should be introduced into the biomass feedstock supply chain as the dominant player. Considering China's vertically integrated political institution, the central and local governments play important roles in the economic and social development. As the bottom of the Chinese bureaucracy, the villagers' committee has huge impact on the rural political, economic and social lives. This kind of introduction could be implemented through being included in the responsibility regulation of the villagers' committee, or the performance assessment for village officials. Based on this research, incorporating the rural official organization could benefit the feedstock supply chain by giving full play to the influence of the villagers' committee on farmers' economic behaviors, avoiding the volatility of contracts and the high transaction costs of working with numerous farmers, and reducing the markup in the intermediate links.

Secondly, the villagers' committee could be incorporated in the way of establishing cooperation. Specifically, the villagers' committee-cooperation undertakes the responsibilities of organizing some members to collect the biomass feedstock uniformly. It should be noted that because of the decentralized farming in China, the amount of biomass that each farmer has is relatively small. Even the purchasing price rises, income from selling the biomass for each household would be 
inconsiderable. Thus, farmers have much less enthusiasm to collect and supply the feedstock. The centralized collecting model by the villagers' committee could increase efficiency and lower the cost. In addition, the revenue from delivering the feedstock to biomass plants would be mainly used to satisfy the villagers' demand for infrastructure and public welfares. Through our investigation, the improvement of public welfares could bring more utilities for villagers. The study recommends this kind of introduction to lead to more utilities obtained from participating in the supply chain, beneficial to stimulate farmers' willingness to supply the feedstock.

Thirdly, a preferential feed-in tariff for biomass power is still necessary considering the high cost and other unfavorable conditions of this industry. The sensitivity analysis manifests that in the scenarios without the preferential feed-in tariff, the biomass feedstock supply, plants' profits and farmers' utilities are all unsatisfactory. Currently, China's biomass plants are perplexed by higher purchase and pre-processing costs, which are disadvantaged over conventional power plants. A preferential feed-in tariff is helpful to the maturity of biomass generation industry. This policy, coordinated with the villagers' committee-cooperation supply pattern, could promote the sustainable operation of the biomass feedstock supply chain. At present, the national-level subsidy to biomass plants is granted in a way of the preferential feed-in tariff, which is $0.75 \mathrm{CNY} / \mathrm{kW} \cdot \mathrm{h}$. According to results from this study, we recommend this category of policy be continued, and the level of subsidy be progressively decreased after the villagers' committee-cooperation pattern reaches full maturity.

Last but not least, because in the sensitivity analysis the farmers' opportunity cost, perception of immaterial utility and the proportion of the revenue used for public welfares have significant impact on the performance of the supply model incorporating the villagers' committee, these three factors should be taken into fully account when the local village starts to establish the villagers' committee-cooperation for the biomass feedstock collection. Corresponding to the higher opportunity cost 
and the lower perception of immaterial utility, more excepted utilities should be given to farmers. While making them sense adequate immaterial utility, the villagers' committee should trade off the proportion of the revenue used for public welfares in case of the decrease of biomass supply and plants' profit.

\section{Acknowledgments}

The authors are grateful for the financial support provided by the National Science Foundation of China (Grant No. 71373077), the Major Program of the

National Social Science Fund of China (Grant No. 15ZDB165) and the Special Items Fund of Beijing Municipal Commission of Education and the Fundamental Research Funds for the Central Universities (Grant No. 2015XS35).

\section{References}

Beck, J., Kempener, R., Cohen, B., Petrie, J., 2008. A complex systems approach to planning, optimization and decision making for energy networks. Energy Policy 36, 2803-2813. doi:10.1016/j.enpol.2008.02.040

Bojić, S., Datkov, D., Brcanov, D., Georgijević, M., Martinov, M., 2013. Location allocation of solid biomass power plants: Case study of Vojvodina. Renew. Sustain. Energy Rev. 26, 769-775. doi:10.1016/j.rser.2013.06.039

Chaib-draa, B., Müller, J., 2006. Multiagent based Supply Chain Management. Springer.

Chen, S., Chen, B., 2014. Energy efficiency and sustainability of complex biogas systems: A 3-level emergetic evaluation. Appl. Energy 115, 151-163. doi:10.1016/j.apenergy.2013.10.053

Dai, J., Chen, B., Hayat, T., Alsaedi, A., Ahmad, B., 2015. Sustainability-based economic and ecological evaluation of a rural biogas-linked agro-ecosystem. Renew. Sustain. Energy Rev. 41, 347-355. doi:10.1016/j.rser.2014.08.043

de Oliveira Florentino, H., Pereira Sartori, M.M., 2003. Game theory in sugarcane crop residue and available energy optimization. Biomass and Bioenergy 25, 29-34. doi:10.1016/S0961-9534(02)00189-7

Del Grosso, S., Smith, P., Galdos, M., Hastings, A., Parton, W., 2014. Sustainable energy crop production. Curr. Opin. Environ. Sustain. 9, 20-25. doi:10.1016/j.cosust.2014.07.007

Ebadian, M., Sowlati, T., Sokhansanj, S., Stumborg, M., Townley-Smith, L., 2011. A new simulation model for multi-agricultural biomass logistics system in bioenergy production. Biosyst. Eng. 110, 280-290. doi:10.1016/j.biosystemseng.2011.08.008

Gao, Y., Zuo, T., 2011. The role of villagers' committee in providing public goods of social security. Issues Agric. Econ. 60-67. doi:10.13246/j.cnki.iae.2011.03.013 
Ge, H., Gray, R., Nolan, J., 2015. Agricultural supply chain optimization and complexity: A comparison of analytic vs simulated solutions and policies. Int. J. Prod. Econ. 159, 208-220. doi:10.1016/j.ijpe.2014.09.023

Hao, H., 2008. Technical and economic analysis of direct combustion biomass power generation project. North China Electric Power University.

Hu, M.C., Huang, A.L., Wen, T.H., 2013. GIS-based biomass resource utilization for rice straw cofiring in the taiwanese power market. Energy 55, 354-360. doi:10.1016/j.energy.2013.03.013

Kaundinya, D.P., Balachandra, P., Ravindranath, N.H., Ashok, V., 2013. A GIS (geographical information system)-based spatial data mining approach for optimal location and capacity planning of distributed biomass power generation facilities: A case study of Tumkur district, India. Energy 52, 77-88. doi:10.1016/j.energy.2013.02.011

Larkin, D., Wilson, G., 1995. Object-Oriented Programming and the Objective-C Language. NeXT Dev. Libr. 178.

Liu, J., Wang, S., Wei, Q., Yan, S., 2014. Present situation, problems and solutions of China's biomass power generation industry. Energy Policy 70, 144-151. doi:10.1016/j.enpol.2014.03.028

Liu, L., Ye, J., Zhao, Y., Zhao, E., 2015. The plight of the biomass power generation industry in China - A supply chain risk perspective. Renew. Sustain. Energy Rev. 49, 680-692. doi:10.1016/j.rser.2015.04.151

Manuj, I., Mentzer, J.T., Bowers, M.R., Abt, R.C., 2009. Improving the rigor of discrete-event simulation in logistics and supply chain research. Int. J. Phys. Distrib. Logist. Manag. 39, $172-201$.

Mei, Y., Lou, J., 2014. Green industry of crop residues sprang up [WWW Document]. JSCHINA.COM.CN. URL http://jsnews.jschina.com.cn/system/2014/12/27/023110649.shtml (accessed 6.21.16).

Mobini, M., Sowlati, T., Sokhansanj, S., 2011. Forest biomass supply logistics for a power plant using the discrete-event simulation approach. Appl. Energy 88, 1241-1250. doi:10.1016/j.apenergy.2010.10.016

Moore, S., Durant, V., Mabee, W.E., 2013. Determining appropriate feed-in tariff rates to promote biomass-to-electricity generation in Eastern Ontario, Canada. Energy Policy 63, 607-613. doi:10.1016/j.enpol.2013.08.076

Nasiri, F., Zaccour, G., 2009. An exploratory game-theoretic analysis of biomass electricity generation supply chain. Energy Policy 37, 4514-4522. doi:10.1016/j.enpol.2009.06.008

North, M.J., Collier, N.T., Ozik, J., Tatara, E.R., Macal, C.M., Bragen, M., Sydelko, P., 2013. Complex adaptive systems modeling with Repast Simphony. Complex Adapt. Syst. Model. 1, 3.

Oliveira, J.B., Lima, R.S., Montevechi, J.A.B., 2016. Perspectives and relationships in Supply Chain Simulation: A systematic literature review. Simul. Model. Pract. Theory 62, 166-191. doi:10.1016/j.simpat.2016.02.001 
Rentizelas, A.A., Tolis, A.J., Tatsiopoulos, I.P., 2009. Logistics issues of biomass: The storage problem and the multi-biomass supply chain. Renew. Sustain. Energy Rev. 13, 887-894. doi:10.1016/j.rser.2008.01.003

Robertson, D., 2005. Agent-Based Modeling Toolkits NetLogo, RePast, and Swarm. Acad. Manag. Learn. Educ. 4, 524-527. doi:10.5465/AMLE.2005.19086798

Shastri, Y., Rodríguez, L., Hansen, A., Ting, K.C., 2011. Agent-Based Analysis of Biomass Feedstock Production Dynamics. BioEnergy Res. 4, 258-275. doi:10.1007/s12155-011-9139-1

Sorhansanj, S., Kumar, A., Turhollow, A., 2006. Development and implementation of integrated biomass supply analysis and logistics model (IBSAL). Biomass and Bioenergy 30, 838-847. doi:10.1016/j.biombioe.2006.04.004

Sun, J., Lin, J., Qian, Y., 2013. Game-theoretic analysis of competitive agri-biomass supply chain. J. Clean. Prod. 43, 174-181. doi:10.1016/j.jclepro.2012.12.026

Sun, Y., Wang, R., Liu, J., Xiao, L., Lin, Y., Kao, W., 2013. Spatial planning framework for biomass resources for power production at regional level: A case study for Fujian Province, China. Appl. Energy 106, 391-406. doi:10.1016/j.apenergy.2013.02.003

Tan, Q., Deng, Y., Zhang, X., Zhang, C., Yang, H., 2014a. A study of farmers' willingness and behavior in the comprhensive utilization of agricultural straw. J. Lanzhou Univ. (Social Sci. $42,105-111$.

Tan, Q., Yang, H., Zhang, X., Deng, Y., Wei, Y., 2014b. Measurement Model and Empirical Analysis of Fuel Collection Cost for Biomass Power Generation. Forum Sci. Technol. China. doi:10.13580/j.cnki.fstc.2014.05.021

Tao, Q., 2011. Pilot farmers' cooperative specialized in collecting straw in Chouzhou City [WWW Document]. Chengdu Econ. Dly. URL http://news.chengdu.cn/content/2011-05/22/content_715621.htm?node=346 (accessed 6.21.16).

Viana, H., Cohen, W.B., Lopes, D., Aranha, J., 2010. Assessment of forest biomass for use as energy. GIS-based analysis of geographical availability and locations of wood-fired power plants in Portugal. Appl. Energy 87, 2551-2560. doi:10.1016/j.apenergy.2010.02.007

Wang, H., 2014. The design of biomass to straw-based power plant transportation system. Nanjing University of Aeronautics and Astronautics.

Wang, M., 2014. China's carbon emission goals achievable: Experts [WWW Document]. CRIENGLISH.com. URL http://english.cri.cn/12394/2014/11/14/3684s852484.htm (accessed 5.29.16).

Wang, X., 2009. Research on farmers' behavior during the developement and utilization of biomass-energy in our country. Chinese Academy of Agricultural Sciences.

Wang, Y., 2011. The studies of biomass power generation supply chain cooperation patterns in the game situation. Nanjing University of Aeronautics and Astronautics.

Wei, Q., 2014. Research on supply chain logistics cost of straw for biomass power generation. China Agricultural University. 
Windisch, J., Röser, D., Mola-Yudego, B., Sikanen, L., Asikainen, A., 2013. Business process mapping and discrete-event simulation of two forest biomass supply chains. Biomass and Bioenergy 56, 370-381. doi:10.1016/j.biombioe.2013.05.022

Xu, X., 2012. Analysis of Farmer Specialized Cooperatives: A Domestic Literature-based Discussion. China Rural Surv. 2-13.

Yang, J., Chen, B., 2014a. Emergy analysis of a biogas-linked agricultural system in rural China A case study in Gongcheng Yao Autonomous County. Appl. Energy 118, 173-182. doi:10.1016/j.apenergy.2013.12.038

Yang, J., Chen, B., 2014b. Global warming impact assessment of a crop residue gasification project-A dynamic LCA perspective. Appl. Energy 122, 269-279. doi:10.1016/j.apenergy.2014.02.034

Yu, H., 2011. Simulation and optimizaiotn of feedstcok supply network for biomass power plant. Zhejiang University.

Yu, S., Tao, J., 2009a. Simulation based life cycle assessment of airborne emissions of biomass-based ethanol products from different feedstock planting areas in China. J. Clean. Prod. 17, 501-506. doi:10.1016/j.jclepro.2008.08.022

Yu, S., Tao, J., 2009b. Economic, energy and environmental evaluations of biomass-based fuel ethanol projects based on life cycle assessment and simulation. Appl. Energy 86, S178-S188. doi:10.1016/j.apenergy.2009.04.016

Yu, S., Tao, J., 2009c. Simulation-based life cycle assessment of energy efficiency of biomass-based ethanol fuel from different feedstocks in China. Energy 34, 476-484. doi:10.1016/j.energy.2008.12.015

Yu, S., Tao, J., 2008. Life cycle simulation-based economic and risk assessment of biomass-based fuel ethanol (BFE) projects in different feedstock planting areas. Energy 33, 375-384. doi:10.1016/j.energy.2007.10.009

Yu, X., 2014. Villagers' committe's behaviors, cadres' characters and farmers' income--An emprical analysis based on data of CFPS 2010. J. Agrotechnical Econ. doi:10.13246/j.cnki.jae.2014.07.006

Zhang, F., Johnson, D.M., Johnson, M.A., 2012. Development of a simulation model of biomass supply chain for biofuel production. Renew. Energy 44, 380-391. doi:10.1016/j.renene.2012.02.006

Zhang, Q., Watanabe, M., Lin, T., DeLaquil, P., Wang, G., Alipalo, M.H., 2010. Rural Biomass Energy 2020 in the People's Republic of China, Asian Development Bank.

Zhang, Q., Zhou, D., Zhou, P., Ding, H., 2013. Cost Analysis of straw-based power generation in Jiangsu Province, China. Appl. Energy 102, 785-793. doi:10.1016/j.apenergy.2012.08.032

Zhang, S., Jiang, J., Luan, J., Lan, X., Di, F., 2014. The analysis and inspiration of scale operation in agricultural process of United Stated and Japan. Issues Agric. Econ. 35, 101-109. doi:10.13246/j.cnki.iae.2014.01.015

Zhao, X., Wang, J., Liu, X., Feng, T., Liu, P., 2012. Focus on situation and policies for biomass power generation in China. Renew. Sustain. Energy Rev. 16, 3722-3729. doi:10.1016/j.rser.2012.03.020 
Zhao, Z., Yan, H., 2012. Assessment of the biomass power generation industry in China. Renew. Energy 37, 53-60. doi:10.1016/j.renene.2011.05.017

Zheng, S., Wang, Z., Awokuse, T.O., 2012. Determinants of producers' participation in agricultural cooperatives: Evidence from Northern china. Appl. Econ. Perspect. Policy 34, 167-186. doi:10.1093/aepp/ppr044

Zhou, X., 2012. The first cooperative specilized in biomass feedstock in the prefecture was established in Yongshun County [WWW Document]. xxz.gov.cn. URL http://www.xxz.gov.cn/rukou/bumen/zzfzssydw_3936/jishou_4103/text/201301/t20130115_6 3925.html (accessed 6.21.16). 
Table 1

Farmer agent's behavior functions.

\begin{tabular}{|c|c|c|c|}
\hline Pattern & Item & Function & \\
\hline \multirow{4}{*}{1} & Objective & $u_{\mathrm{F}_{i}}=\max \left\{\ln c_{\mathrm{F}_{i}, 2}, \ln \pi_{\mathrm{F}_{i}}\right\}$ & (2) \\
\hline & Profit & $\pi_{\mathrm{F}_{i}}=\left(p_{\mathrm{P}}+s\right) Q_{i}-\frac{2}{3} c_{\mathrm{F}_{i}, 1} Q_{i}^{\frac{3}{2}} \quad \mathrm{a}$ & (3) \\
\hline & Quantity decision & $Q_{i}=\left\{\begin{array}{l}0, \ln c_{\mathrm{F}_{i}, 2} \geq \ln \pi_{\mathrm{E}, \mathrm{F}_{i}} \\
q_{i}, \ln c_{\mathrm{F}_{i}, 2}<\ln \pi_{\mathrm{E}, \mathrm{F}_{i}}\end{array}\right.$ & (4) \\
\hline & Expected profit & $\pi_{\mathrm{E}, \mathrm{F}_{i}}=\left(p_{\mathrm{P}}+s\right) q_{i}-\frac{2}{3} c_{\mathrm{F}_{i}, 1} q_{i}^{\frac{3}{2}}$ & (5) \\
\hline \multirow{4}{*}{2} & Objective & $u_{\mathrm{F}_{j i}}=\max \left\{\ln c_{\mathrm{F}_{j i}, 2}, \ln \pi_{\mathrm{F}_{j i}}\right\}$ & (6) \\
\hline & Profit & $\pi_{\mathrm{F}_{j i}}=\left(p_{\mathrm{B}_{j}}+s\right) Q_{j i}-\frac{2}{3} c_{\mathrm{F}_{j i}, 1} Q_{j i}^{\frac{3}{2}}$ & (7) \\
\hline & Quantity decision & $Q_{j i}=\left\{\begin{array}{l}0, \ln c_{\mathrm{F}_{j i}, 2} \geq \ln \pi_{\mathrm{E}, \mathrm{F}_{j i}} \\
q_{j i}, \ln c_{\mathrm{F}_{j i}, 2}<\ln \pi_{\mathrm{E}, \mathrm{F}_{j i}}\end{array}\right.$ & (8) \\
\hline & Expected profit & $\pi_{\mathrm{E}, \mathrm{F}_{j i}}=\left(p_{\mathrm{B}_{j}}+s\right) q_{j i}-\frac{2}{3} c_{\mathrm{F}_{j i},} q_{j i}^{\frac{3}{2}}$ & (9) \\
\hline \multirow{4}{*}{3} & Objective & $u_{\mathrm{F}_{j i}}=\max \left\{\ln c_{\mathrm{F}_{j i}, 2}, \ln \pi_{\mathrm{F}_{j i}}+\omega_{\mathrm{F}_{j i}} \ln \gamma_{j} \pi_{\mathrm{C}_{j}}\right\}$ & (10) \\
\hline & Profit & $\pi_{\mathrm{F}_{j i}}=\left(p_{\mathrm{P}} Q_{j i}-\frac{2}{3} c_{\mathrm{F}_{j i}, 1} Q_{j i}^{\frac{3}{2}}-c_{\mathrm{C}_{j}} Q_{j i}\right)\left(1-\gamma_{j}\right)+s Q_{j i}$ & $(11)$ \\
\hline & Quantity decision & $Q_{j i}=\left\{\begin{array}{l}0, \ln c_{\mathrm{F}_{j i}, 2} \geq \ln \pi_{\mathrm{E}, \mathrm{F}_{j i}}+\omega_{\mathrm{F}_{j i}} \ln \gamma_{j} \pi_{\mathrm{c}_{j}}^{(t-1)} \\
q_{j i}, \ln c_{\mathrm{F}_{j i}, 2}<\ln \pi_{\mathrm{E}, \mathrm{F}_{j i}}+\omega_{\mathrm{F}_{j i}} \ln \gamma_{j} \pi_{\mathrm{c}_{j}}^{(t-1)}\end{array}\right.$ & (12) \\
\hline & Expected profit & $\pi_{\mathrm{E}, \mathrm{F}_{j i}}=\left(p_{\mathrm{P}} q_{j i}-\frac{2}{3} c_{\mathrm{F}_{j j}, 1} q_{j i}^{\frac{3}{2}}-c_{\mathrm{C}_{j}} q_{j i}\right)\left(1-\gamma_{j}\right)+s q_{j i}$ & (13) \\
\hline
\end{tabular}

${ }^{\mathrm{a}}$ Referring to Wang (2011).

Table 2

Action sequence of agents in a given round.

\begin{tabular}{ccc}
\hline Priority & Agent & \multicolumn{1}{c}{ Action } \\
\hline 0 & Plant & $\begin{array}{l}\text { Offering the purchase price } p_{\mathrm{P}} \text { under the } \\
\text { feedback regulation to achieve maximum profit } \\
\end{array}$ \\
& Setting the price of buying biomass from farmers \\
-1 & $p_{\mathrm{B}_{j}}$ to ensure a certain profit rate
\end{tabular}



-2 Farmer Deciding on the supply amount $Q_{i}$ or $Q_{j i}$
based on the utility comparison
Calculating the sum of biomass purchased from

Broker farmers $Q_{j}$

$-3$

Calculating the sum of biomass members' supply

Cooperative $\quad Q_{j}$ and then the profit $\pi_{\mathrm{C}_{j}}$

$\begin{array}{ll}-4 & \text { Calculating the sum of biomass } Q \text { purchased } \\ \text { from farmers, brokers or cooperatives }\end{array}$

Table 3

Parametric assumptions of context.

\begin{tabular}{ccccc}
\hline Parameter & Unit & Pattern 1 & Pattern 2 & Pattern 3 \\
\hline$N^{\mathrm{a}}$ & - & 500 & 500 & 500 \\
$M^{\mathrm{a}}$ & - & - & 10 & 10 \\
$N_{j}{ }^{\mathrm{a}}$ & - & - & 50 & 50 \\
$p_{\mathrm{e}}{ }^{\mathrm{b}}$ & $\mathrm{CNY} / \mathrm{kW} \cdot \mathrm{h}$ & 0.75 & 0.75 & 0.75 \\
$s^{\mathrm{c}}$ & $\mathrm{CNY} / \mathrm{t}$ & 0 & 0 & 0 \\
\hline
\end{tabular}

${ }^{\mathrm{a}}$ Assumed for the simulation.

${ }^{\mathrm{b}}$ According to the Notice on Improvement of the Pricing Policy for the Agricultural and Forest Biomass-based Electricity.

${ }^{\mathrm{c}}$ The common scenario in China.

\section{Table 4}

Parametric assumptions of agents.

\begin{tabular}{cccccc}
\hline \multirow{2}{*}{ Agent } & Parameter & Unit & Pattern 1 & Pattern 2 & Pattern 3 \\
\hline \multirow{4}{*}{ Plant } & $\eta^{\mathrm{a}}$ & $\mathrm{kW} \cdot \mathrm{h} / \mathrm{t}$ & 650 & 650 & 650 \\
& $p_{\mathrm{P}}^{(1) \mathrm{b}}$ & $\mathrm{CNY} / \mathrm{t}$ & 300 & 300 & 300 \\
& $\Delta p_{\mathrm{P}}{ }^{\mathrm{c}}$ & $\mathrm{CNY} / \mathrm{t}$ & 5 & 5 & 5 \\
& $c_{\mathrm{P}}{ }^{\mathrm{d}}$ & $\mathrm{CNY} / \mathrm{t}$ & 160 & 50 & 50 \\
& $c_{F_{i}, 1} / c_{F_{j i}, 1}{ }^{\mathrm{e}}$ & - & $N\left(150,25^{2}\right)$ & $N\left(150,25^{2}\right)$ & $N\left(60,25^{2}\right)$ \\
& $c_{F_{i}, 2} / c_{F_{j i}, 2}{ }^{\mathrm{f}}$ & $\mathrm{CNY}$ & $N\left(250,50^{2}\right)$ & $N\left(250,50^{2}\right)$ & $N\left(250,50^{2}\right)$
\end{tabular}




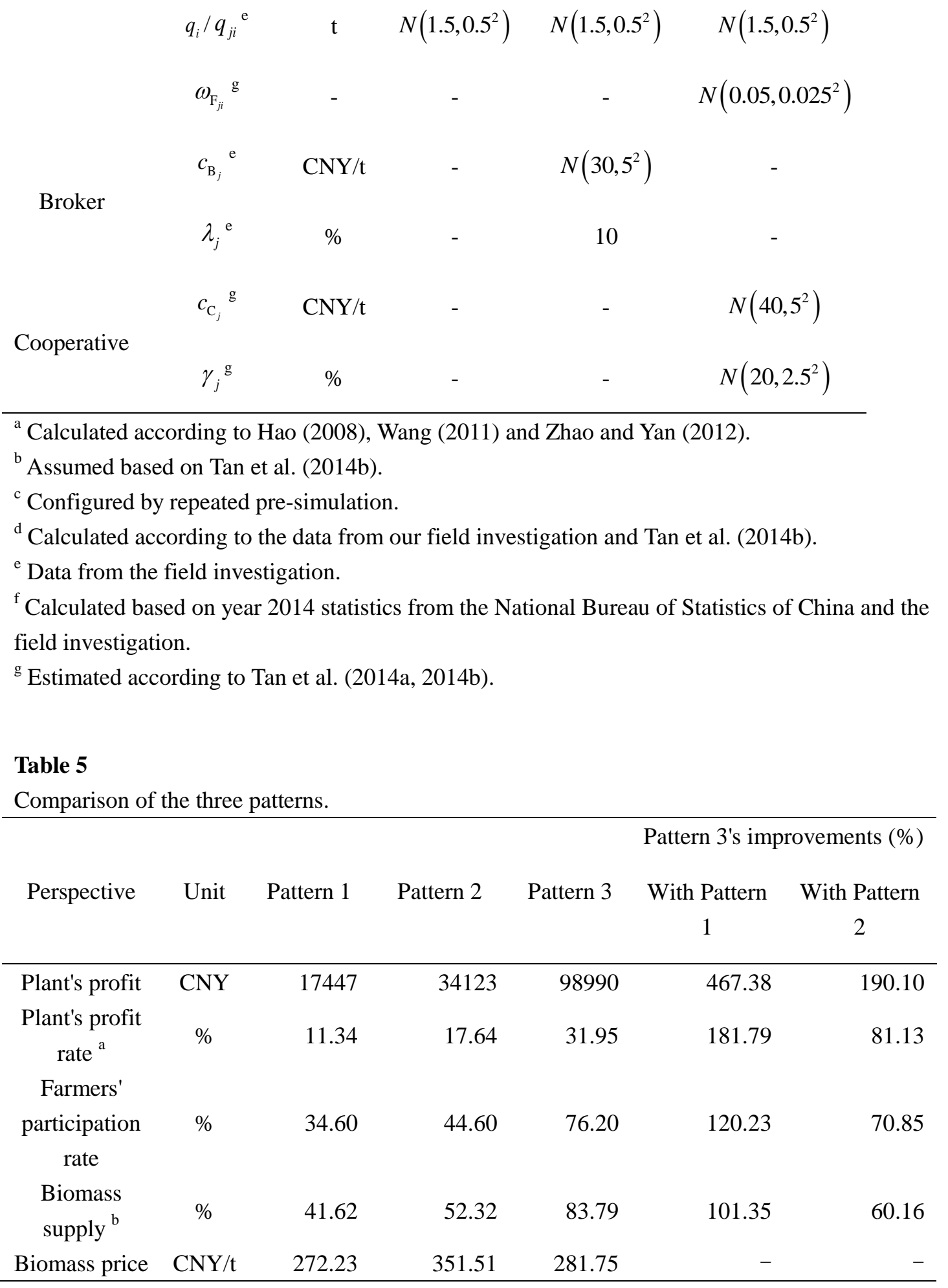

${ }^{\mathrm{a}}$ Calculated by Eq. (17).

${ }^{\mathrm{b}}$ In percentage of the gross biomass amount farmers possessed.

\section{Table 6}

Performance of the supply chain in different combinations of feed-in tariff and subsidy.

$\begin{array}{llll}\text { Scenario } & \text { Feed-in } & \text { Subsidy } & \text { Plant's profit (CNY) Biomass supply (\%) }\end{array}$




\begin{tabular}{|c|c|c|c|c|c|c|c|c|}
\hline & $\begin{array}{c}\text { tariff } \\
(\mathrm{CNY} / \mathrm{k} \\
\mathrm{W} \cdot \mathrm{h})\end{array}$ & $(\mathrm{CNY} / \mathrm{t})$ & $\begin{array}{c}\text { Pattern } \\
1\end{array}$ & $\begin{array}{l}\text { Pattern } \\
2\end{array}$ & $\begin{array}{c}\text { Pattern } \\
3\end{array}$ & $\begin{array}{c}\text { Pattern } \\
1\end{array}$ & $\begin{array}{c}\text { Pattern } \\
2\end{array}$ & $\begin{array}{c}\text { Pattern } \\
3\end{array}$ \\
\hline 1 & 0.75 & 0 & 16330 & 32565 & 96144 & 40.25 & 47.32 & 80.04 \\
\hline 2 & 0.40 & 60 & 0 & 401 & 19661 & 0.00 & 3.06 & 42.86 \\
\hline 3 & 0.75 & 60 & 41350 & 65941 & 136841 & 67.16 & 71.61 & 84.30 \\
\hline
\end{tabular}

${ }^{\mathrm{a}}$ In percentage of the gross biomass amount farmers possessed. 


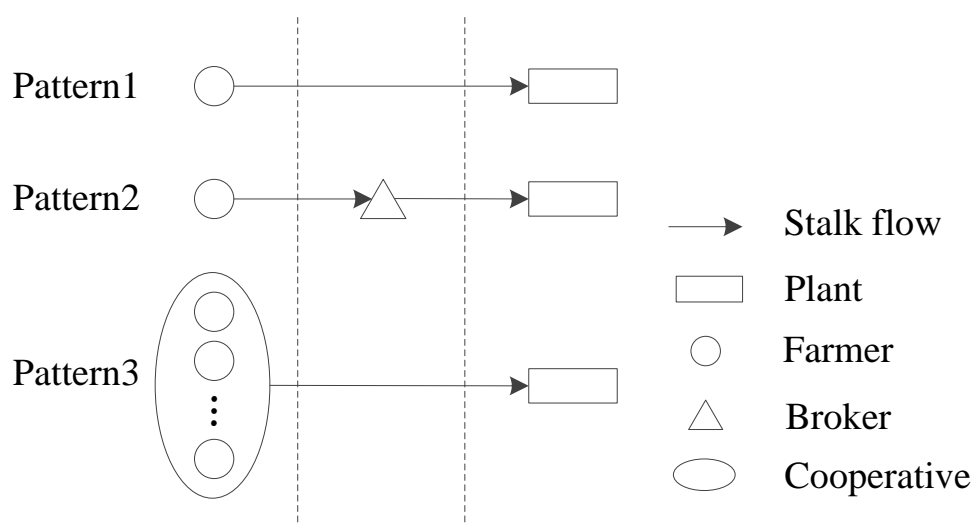

Fig. 1. Feedstock supply chains in the three patterns.

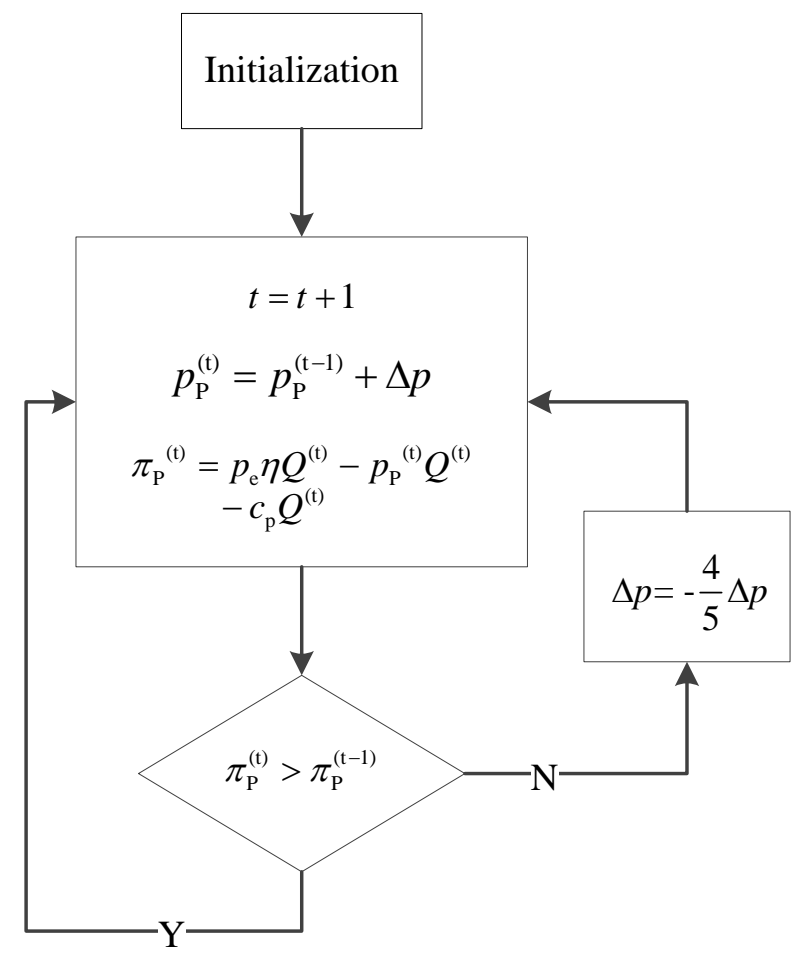

Fig. 2. The process of a plant agent's adjusting the purchase price.

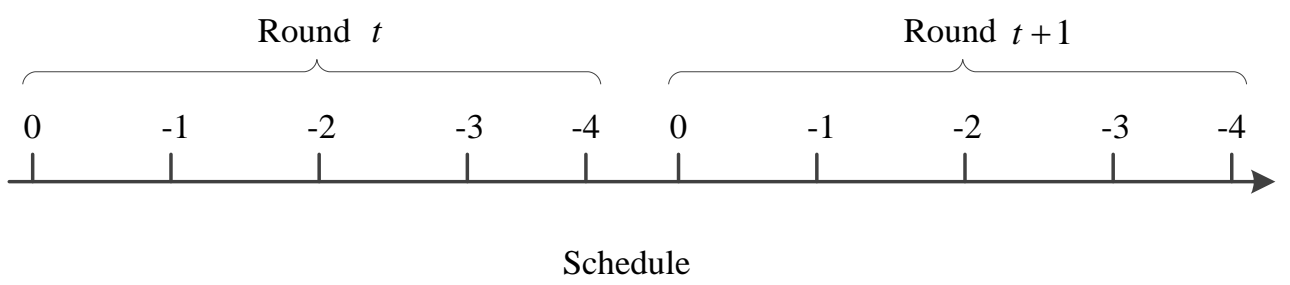

Fig. 3. Simulation schedule of the biomass feedstock supply chain. 


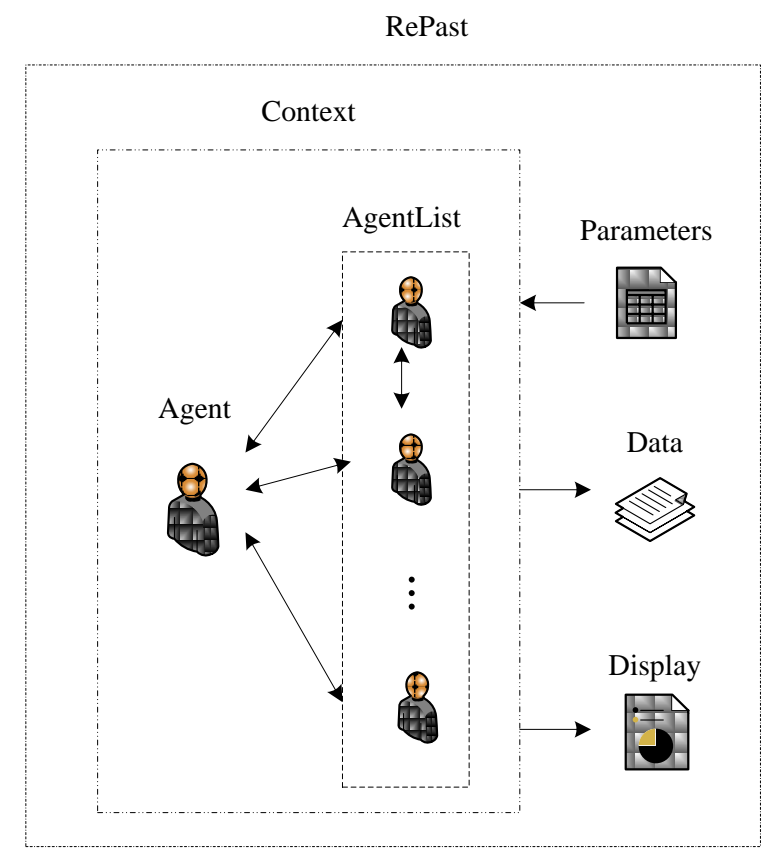

Fig. 4. Architecture of RePast.

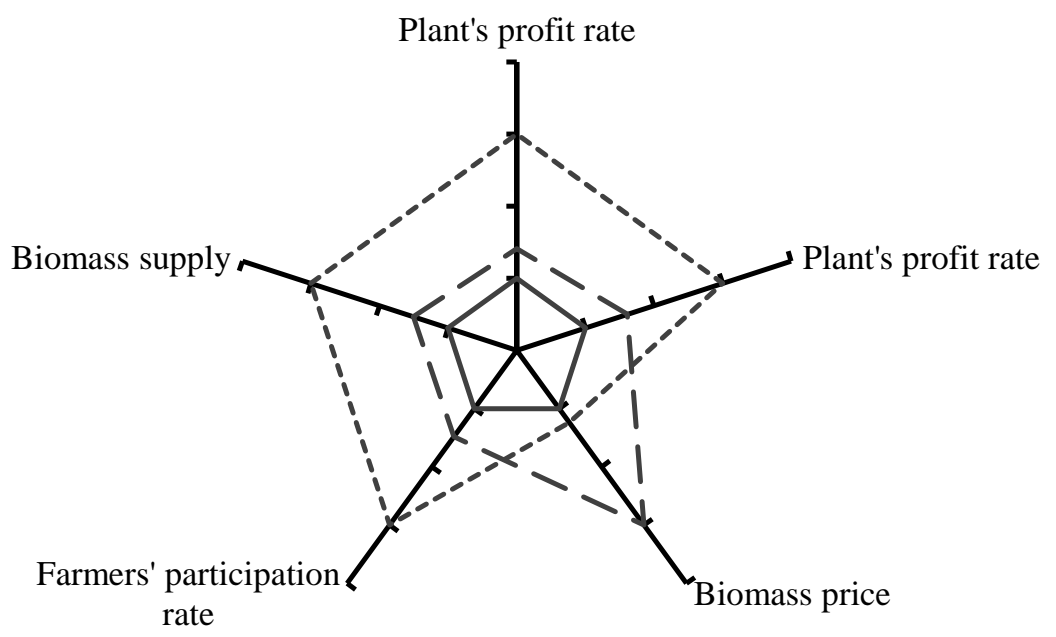

Pattern $1 \quad$ - - Pattern $2 \quad$----- Pattern 3

Fig. 5. Spider chart of pattern comparison. 

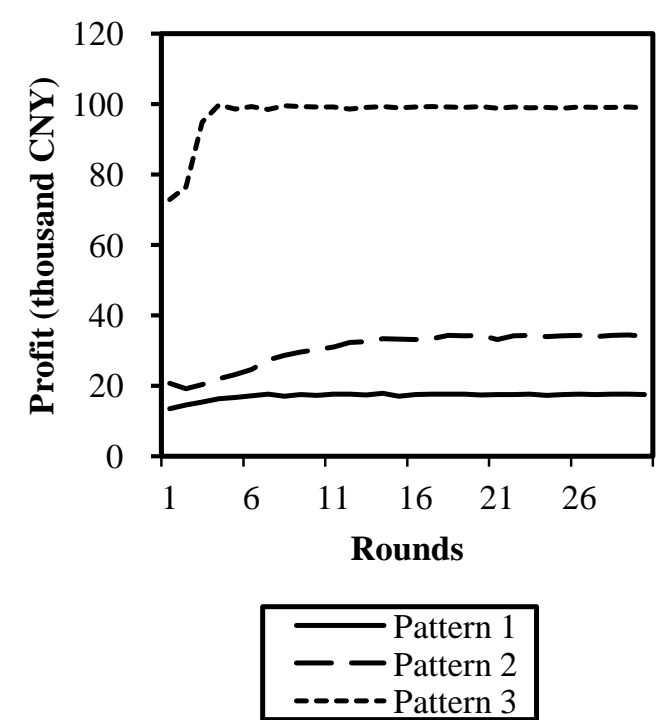

(a)

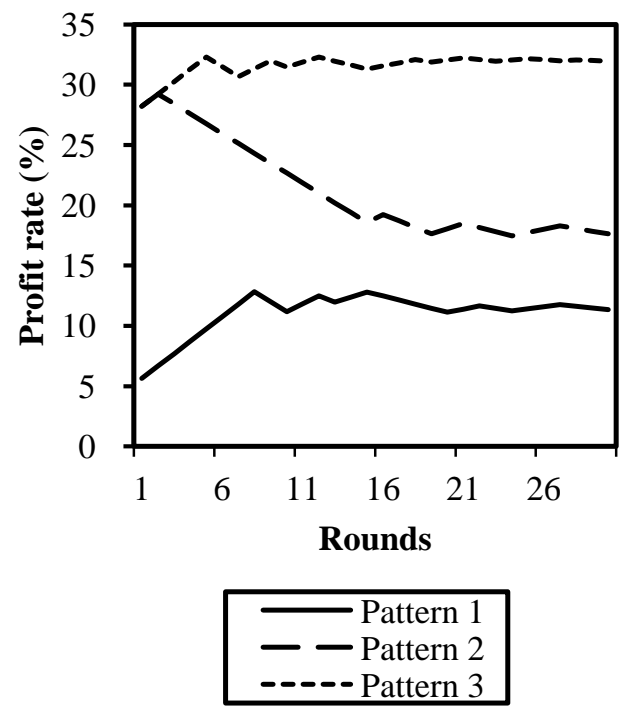

(b)

Fig. 6. Profile of plant's (a) profit and (b) profit rate.

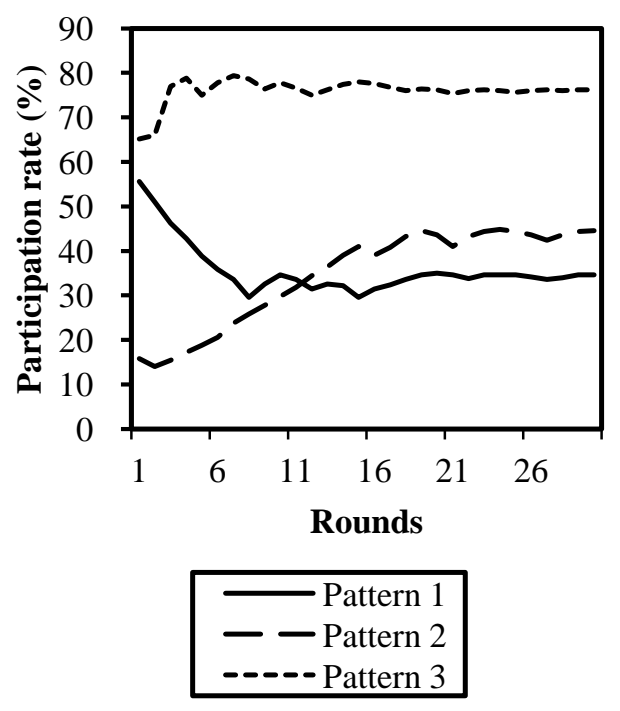

(a)

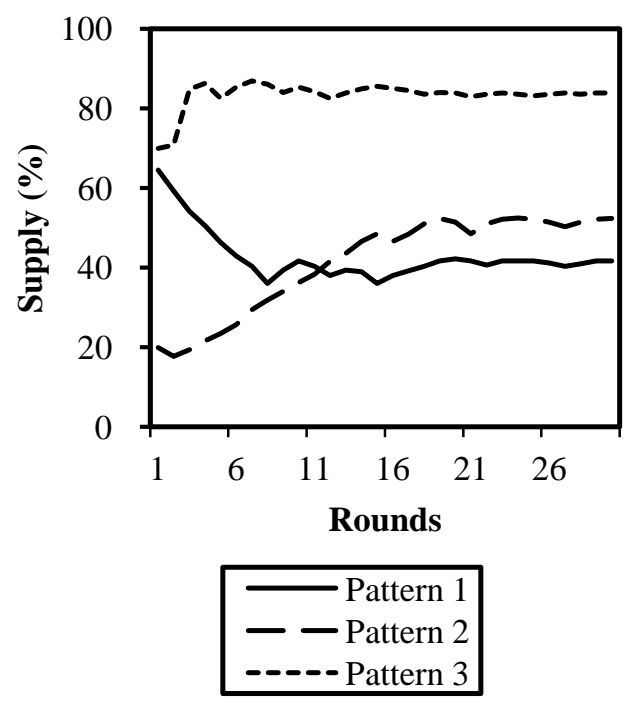

(b)

Fig. 7. Profile of (a) farmers' participation and (b) biomass supply. 


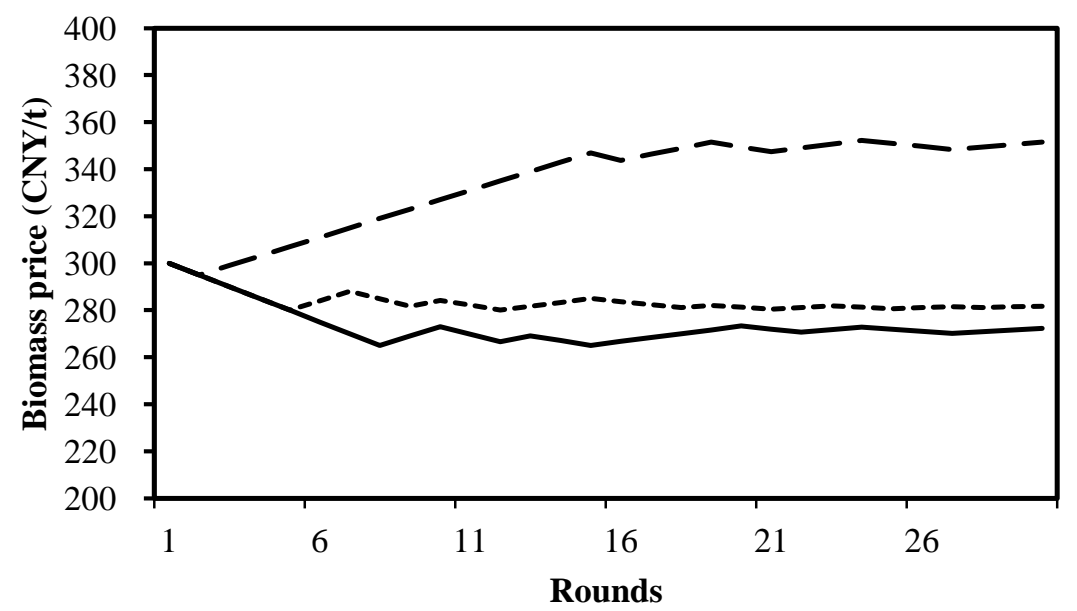

Pattern $1 \quad$ - - Pattern 2 ------ Pattern 3

Fig. 8. Profile of biomass price.

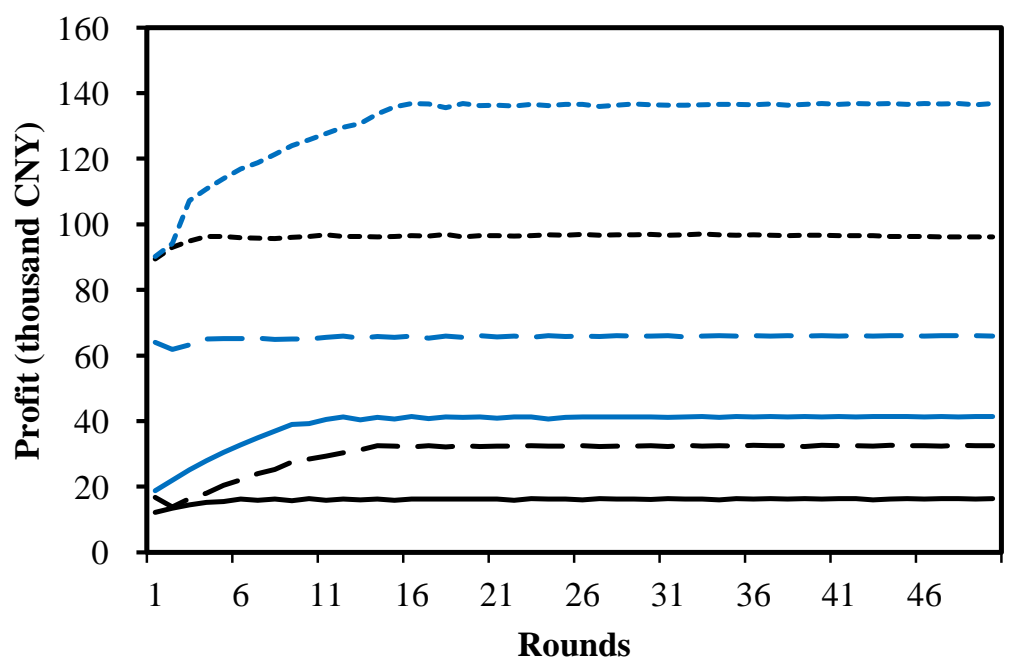

- Scenario 1 Pattern 1 - Scenario 1 Pattern 2 ------Scenario 1 Pattern 3 Scenario 3 Pattern 1 - - Scenario 3 Pattern 2 ------ Scenario 3 Pattern 3

Fig. 9. Profiles of plant's profit in scenarios 1 and 3. 


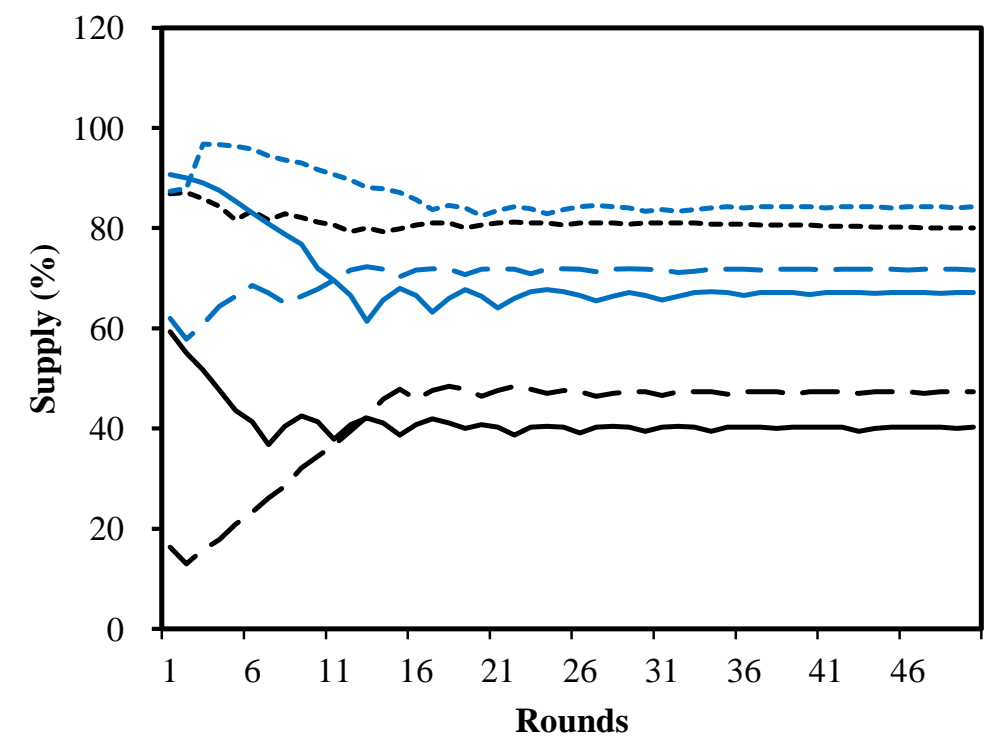

- Scenario 1 Pattern 1 - Scenario 1 Pattern 2 -----Scenario 1 Pattern 3 Scenario 3 Pattern 1 - Scenario 3 Pattern 2 ------ Scenario 3 Pattern 3

Fig. 10. Profiles of biomass supply in scenarios 1 and 3 .

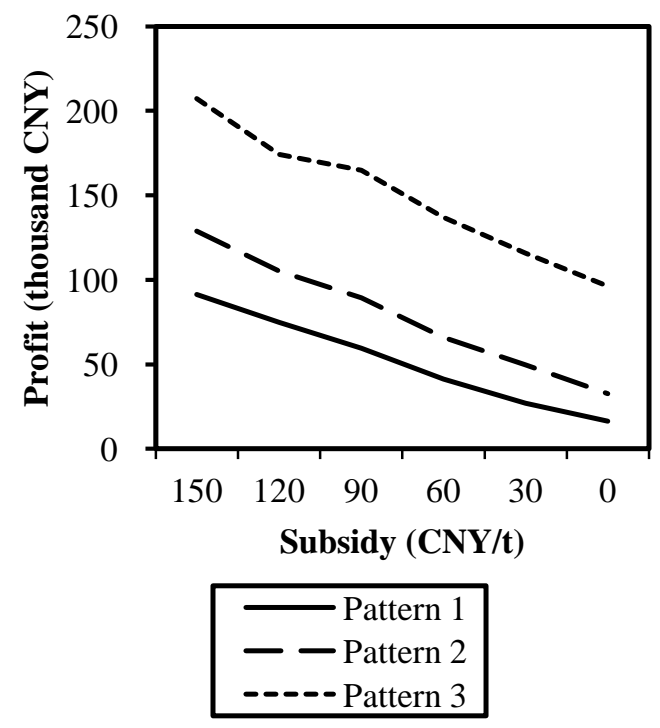

(a)

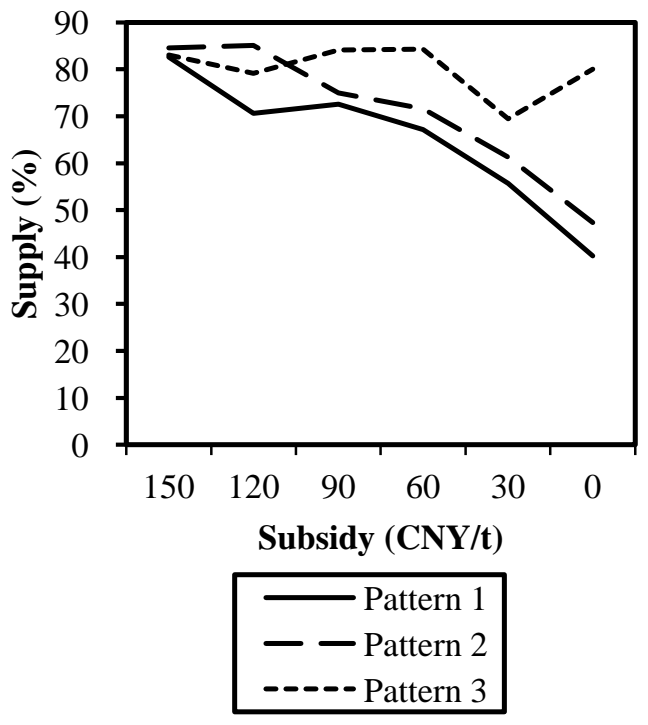

(b)

Fig. 11. Stable (a) plant's profit and (b) biomass supply at different subsidy levels. 


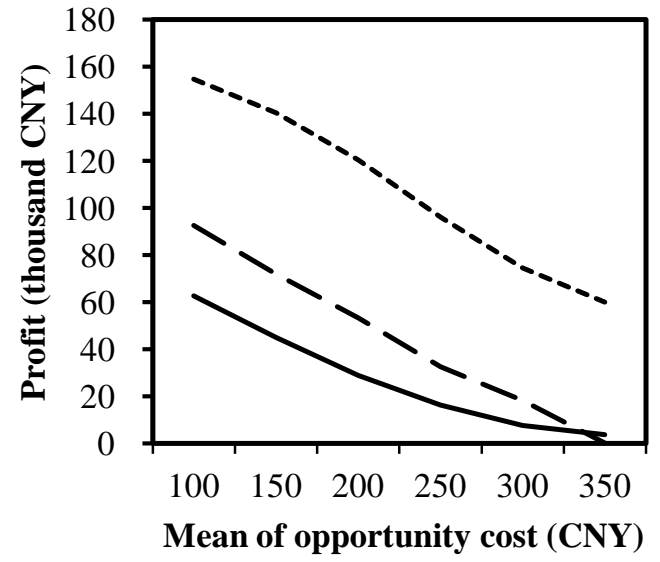

$$
\begin{aligned}
& \text { - Pattern } 1 \\
& \text { - - Pattern } 2 \\
& \text {----- Pattern } 3
\end{aligned}
$$

(a)

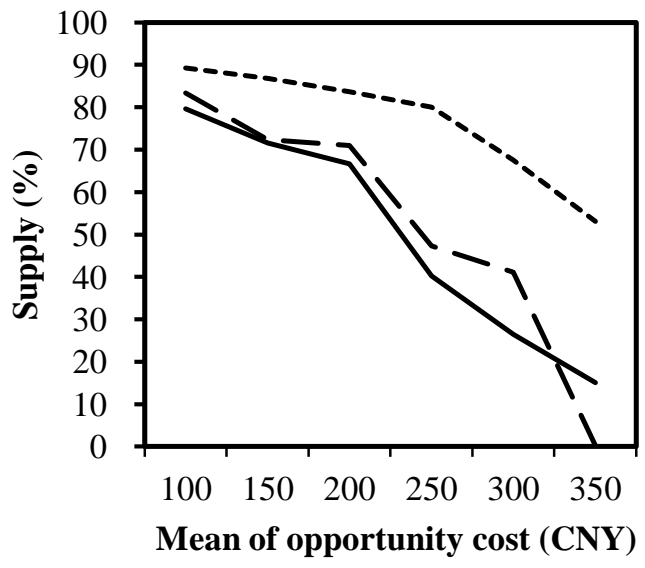

$$
\begin{aligned}
& \text { - Pattern } 1 \\
& - \text { - Pattern } 2 \\
& \text {----- Pattern } 3
\end{aligned}
$$

(b)

Fig. 12. Stable (a) plant's profit and (b) biomass supply at different opportunity cost levels.

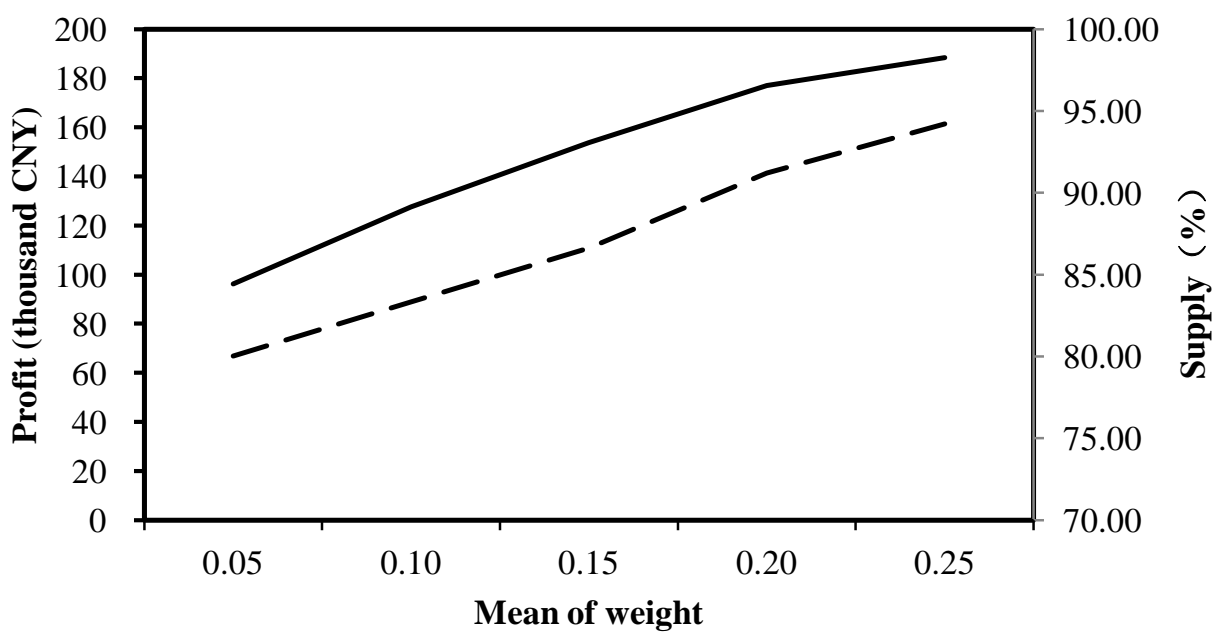

$$
\text { - Profit }- \text { - Supply }
$$

Fig. 13. Stable plant's profit and biomass supply at different weight levels. 

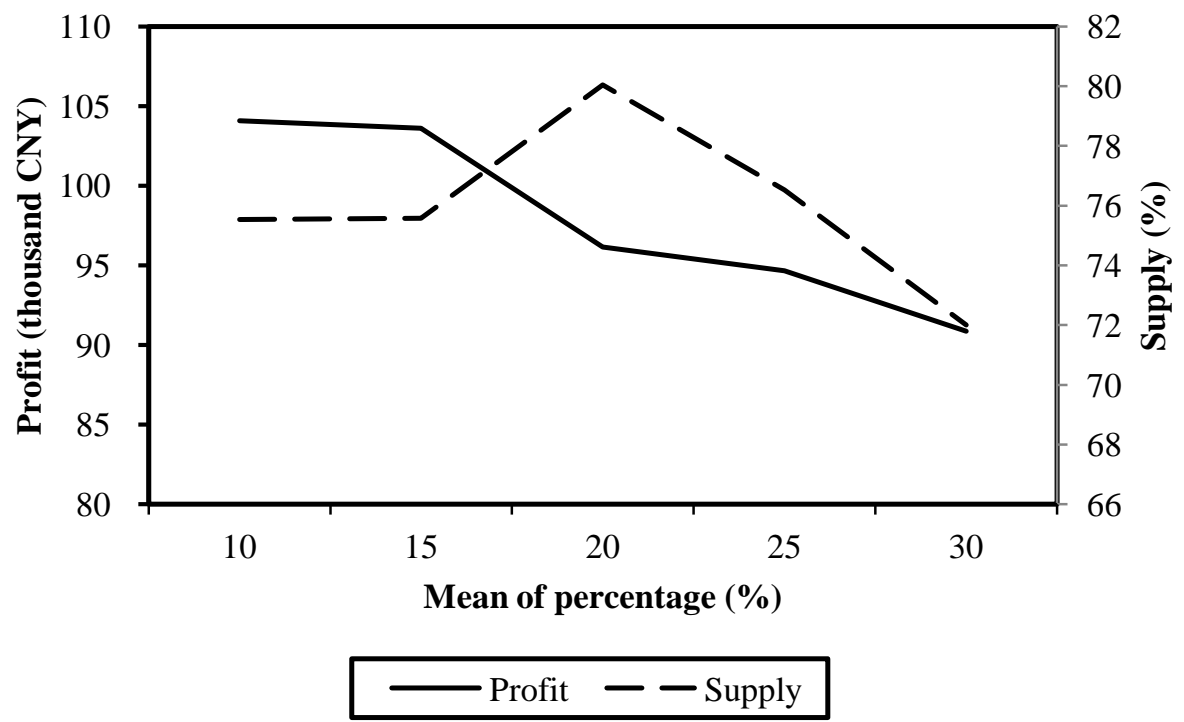

Fig. 14. Stable plant's profit and biomass supply at different foundation percentage levels. 